Elsevier Editorial System(tm) for Energy Manuscript Draft

Manuscript Number: EGY-D-17-04419R5

Title: A novel network data envelopment analysis model for performance measurement of Turkish electricity distribution companies

Article Type: Full length article

Keywords: Network DEA; Profit efficiency; Directional Distance Function; Energy production

Corresponding Author: Dr. Konstantinos Petridis, Ph.D.

Corresponding Author's Institution: University of Macedonia

First Author: Konstantinos Petridis, Ph.D.

Order of Authors: Konstantinos Petridis, Ph.D.; Mehmet G Ünsal, PhD; Prasanta K Dey, PhD (Engineering); Hasan H Örkcü, PhD

Abstract: Electricity distribution companies have a significant role for both households and industries. Benchmarking of the electricity distribution companies in the energy sector has become a subject that is studied widely nowadays due to the effect of privatization policies for developing countries. Since there are multiple production stages regarding the generation and supply procedures of electricity power, Network DEA technique is used.Directional Distance Function is also integrated into Network DEA technique. Electricity distribution companies aim at maximizing profit while minimizing the expenses. The main problem is how the profit idea can be integrated into the evaluation process. The aim of the proposed model is to evaluate profit efficiency of electricity distribution companies while taking into account expansion cost for additional energy supply. This two stage approach is applied to Turkish electricity distribution companies. Results are presented based on radial and profit efficiency measures. The proposed model is effective as provides realistic results considering the expenses and incomes of distribution companies. 
To the editor

Dear Sir,

We revised our paper for forth time according to comments of Reviewer 8. Actually, theoretical and application part contributions of the paper are now clearly demonstrated.

According to comments of reviewer, all points were clarified. The introduction and review parts of paper were divided. We revised the methodology section. And we corrected all the typos.

We hope to have a final decision and met the quality of the journal and stress out the novelty of the article for possibble publication in Energy journal.

Best regards,

The authors 
Reviewers' comments:

Reviewer \#8:

1.Introduction is too long (all dumped together), I suggest author(s) divide into multiple sub-heading/ separate introduction and literature review so that readers can understand more clearly.

2.Page 6: first sentence: Recently, investigation of performance of ... especially for energy journals"--- it would be better if author(s) specify the research domain rather where those topics are appeared in particular kind of journals.

3.Please correct table number, table 1 should be table 2 or probably you need to present nomenclature in different format, if you decide to present in tabular format please provide suitable caption.

4.Page 4 second paragraph: is about methodology, where author can separate into literature review part (methodology section) The paper has presented similar information with different presentation style which is confusing.

5.The paper has several typos for instance in page 26 first paragraph last sentence "....applird...."

6.Paper used electricity distribution companies but in discussion section, author(s) mentioned that electricity distribution companies are also the supplier for electrical transmission system. Which is either confusing or needs further justification. 7.In discussion section page 27 second paragraph, " The companies have been --region of Turkey" can be moved in earlier section.

Thank you for your valuable comments, we tried to adress to all of your suggestions as below;

1. We seperated introduction part as 1. Introduction section and 2. Common Used Variables in Literaturev Survey of Electric Distribution Sector Efficiency section.

2. According to your advice, we specified the sentences as follows: "Recently, investigation of performance of electric distribution companies is very popular subject for developing countries", now it focus on the research subject rather than journal names.

3. Table numbers are corrected and, all notations and indices are described and presented in Appendix as nomenclature part for the models in subsections of this section. 
4. We moved this paragraph into section 2 which is mentioned above, and we modified it to make it much more suitable the concept of the section as below:

\section{Common Used Variables in Literaturev Survey of Electric Distribution Sector Efficiency}

Data Envelopment Analysis (DEA) uses input(s) and output(s) variables in the efficiency measurement process. According to Retzlaff-Roberts (1996), it is suggested that the concept of positive and negative effective variables method is preferred to the classical concept of input and output variables. According to his study, the variables where an increase is reported provide better evaluation of the unit and these variables are considered as positive effective variables. This idea of Retzlaff-Roberts (1996) and the studies in the literature about measuring the performance of electric distribution companies will be guide in the variable selection process for this study.

5. We checked the typos of the paper.

6. At this point, we tried to figure out the importance of distribution companies in transmission of electricity, then we addressed to the idea which says the profit can be a tool for them, and they can be investigated from the aspect of profitability similar to transmission system. We modified the paragraph to indicate this point.

7. We moved this paragraph into the first paragraph of the application section.

Thank you again, all of your valuable comments. 
- A Network DEA model for performance measurement of Turkish electricity companies

- Integration of expansion cost

- Electricity distribution companies are ranked based on profit efficiency measure

- Real life application of the model to 20 electricity distribution companies 


\author{
A novel network data envelopment analysis model for performance measurement \\ of Turkish electric distribution companies \\ ${ }^{a}$ Department of Applied Informatics, 156 Egnatia str., 54006, Thessaloniki, Greece \\ ${ }^{\mathrm{b}}$ Department of Statistics, Art and Science Faculty, Uşak University, Main Campus, Uşak, \\ Turkey \\ ${ }^{c}$ Operations and Information Management, Aston Business School, Aston University, \\ Birmingham, UK \\ ${ }^{\mathrm{d}}$ Department of Statistics, Science Faculty, Gazi University, Teknikokullar Beşevler, Ankara, \\ Turkey
}

*Corresponding author, e-mail: k.petridis@uom.edu.gr, Tel: +30 2310891728 


\begin{abstract}
Electric distribution companies have a significant role for both households and industries. Benchmarking of the electric distribution companies in the energy sector has become a subject that is studied widely nowadays due to the effect of privatization policies for developing countries. Since there are multiple production stages regarding the generation and supply procedures of electric power, Network DEA technique is used._Directional Distance Function is also integrated into Network DEA technique. Electric distribution companies are organizations that are aiming at maximizing profit while minimizing the expenses. The main problem is how the profit idea can be integrated into the evaluation process. The aim of the proposed model is to evaluate profit efficiency of electric distribution companies while taking into account expansion cost for additional energy supply. This two stage approach is applied to Turkish electric distribution companies. Results are presented based on radial and profit efficiency measures. The proposed model is demonstrates_realistic results by considering the expenses and incomes of distribution companies.
\end{abstract}

Keywords: Network DEA, Profit efficiency, Directional Distance Function, Electric Distribution

JEL Classification: C6, Q4 


\section{Introduction}

Aiming to liberalize the distribution sector in Turkey, privatization in electric distribution sector started in 2004 and completed in 2010, within the legislation framework of Electricity Market Law and according to the Privatization High Council decree no. 2004/22, dated April 02, 2004 (Official Newspaper of Republic of Turkey, No: 25422, Ankara, Turkey; 2004). In 1994, TEİAŞ (Turkey Electric distribution companies Corporation) started to operate officially with the aim of reaching optimum productivity and maximum profitability in services; TEİAŞ is responsible for supplying electrical energy to the customers from large cities to small residential areas (TEİAŞ Annual Statistical Reports, 2011). Various projects were completed or were in progress to evaluate and assist management, planning and operations of electric power distribution. Besides these operational projects, statistics related to electricity distribution and annual reports were included in publications (TEİAŞ Annual Statistical Reports, 2011; Colak et al., 2014). Furthermore, several numerical data analyses were conducted to evaluate service or distribution performance of electric distribution companies worldwide. Some of these analyses are based on statistical and operational research techniques such as Data Envelopment Analysis (DEA), Stochastic Frontier Analysis (SFA), Malmquist Index, Ordinary Least Squares (OLS) etc.

The first study related to electricity distribution efficiency studycompanies infor Turkey has been investigated by Bagdadioglu et al. (1996). Their study presented a comparison of technical efficiency between public and private electric distribution companies to examine the effect of privatization of electric distribution companies in Turkey. Based on the findings of this study, high performance state-owned electric distribution companies were separated to be privatized. The efficiency analysis of Turkish electric distribution companies has been 
examined, considering number of staffs, operational expenditures as inputs and number of customers, total energy supply as outputs (Örkcü et al., 2015).

Data Envelopment Analysis (DEA) is a non-parametric methodology for the evaluation of relative efficiency of decision making units (DMUs) with common inputs and outputs. The efficiency of each DMU is calculated with the use of Linear Programming (LP). The discrimination of parameters as inputs and outputs depends on their effect on the unit. According to Retzlaff Roberts (1996), it is suggested that the concept of positive and negative effective variables method is preferred to the classical concept of input and output variables. According to his study, the variables where an increase is reported provide better evaluation of the unit and these variables are considered as positive effective variables.

In this paper a new profit efficiency network DEA model is proposed by using a new objective function and threshold value constraints as a modification of Directional Distance Function (DDF) Network DEA approach. Since the analysis examines multiple stages with desirable and undesirable outputs, a DDF Network DEA formulation is selected; DDF models consider simultaneously the maximization of a desirable output and the minimization of an undesirable output for given inputs (Sueyoshi \& Goto, 2011). This novel DEA formulation can take into account undesirable outputs transforming the problem into a profit efficiency model for measuring electric production efficiency. Most DEA models assume that in order to increase efficiency, inputs should be decreased and outputs should be increased. The contribution of the study lies also on the fact that the proposed model takes into account the expansion cost in the case where energy supply should be more than the capabilities of a distribution company. Revenue and cost functions are construced based on desirable and undesirable outputs respectively for profit efficiency of electric distribution companies measurement. From this aspect, although there are several studies in the literature about 
efficiency evaluation of electric distribution companies, this study provides a first investigation of profit efficiency of electric distribution companies by using a novel approach of Network DEA model.

The next sections presents the literature survey and common used variables in electric distribution sector and methodology of DDF Network DEA and two stage DEA model for profit efficiency, respectively. Section 43 presents the structure of two stage DEA process and inputs, outputs and undesirable outputs used in efficiency measurement application of Turkish electric distribution companies. In Section 54 , the empirical results of proposed $\underline{\underline{\text { model }} \text { are demonstrated. The study concludes in Section }} \underline{\underline{6}}$.

\section{Common Used Variables in Literaturev Survey of Electric Distribution Sector Efficiency}

Data Envelopment Analysis (DEA) uses input(s) and output(s) variables in the efficiency measurement process. According to Retzlaff-Roberts (1996), it is suggested that the concept of positive and negative effective variables method is preferred to the classical concept of input and output variables. According to his study, the variables where an increase is reported provide better evaluation of the unit and these variables are considered as positive effective variables. This idea of Retzlaff-Roberts (1996) and the studies in the literature about measuring the performance of electric distribution companies will be guide in the variable $\underline{\text { selection process for this study. }}$

ByBy considering both the concept of Retzlaff-Roberts (1996) and the studies in the literature about measuring the performance of electric distribution companies, some generalizations can be made about which variables/indicators should be used as inputs or outputs in performance measurement process of electric distribution companies. Total energy supply data is defined as the sum of net consumption and energy losses. Energy supply is an output 
in electricity distribution process for electric distribution companies (Yunos and Hawdon, 1997; Forsund and Kittelsen, 1998; Korhonen and Syrjanen, 2003; Edvardsen and Forsund, 2003; Giannakis et al., 2005; Hess and Cullman, 2007; Bagdadioglu et al., 2007; Souza et al., 2010). In relevant studies, Net consumption variable is treated as input for assessing efficiency of electric distribution companies. Energy losses variable is widely used for this kind of efficiency measurement studies as seen from the studies in literature (Forsund and Kittelsen, 1998; Pahwa et al., 2002; Jamasb and Pollitt, 2003; Edvardsen and Forsund, 2003). Nevertheless, energy losses variable has a negative sign and can be considered as an undesirable output in the electric power distribution process. Annual faults and interruptions have same structure with energy losses in electricity distribution, thus this variable can be considered as undesirable output (Korhonen and Syrjanen, 2003; Giannakis et al., 2005; Yadav et al., 2011; Filippini and Wetzel, 2014; Gouveia et al., 2015, Sueyoshi \& Goto, 2016). Furthermore, number of customers is considered as one of the most common output variables for efficiency measurement and for service efficiency of electric distribution companies (Goto and Tsutsui, 1998; Zhang and Bartels, 1998; Pombo and Taborda, 2006; Cullman and Hirschhausen, 2006; Yadav et al., 2011; Gouveia et al., 2015; Örkcü et al.,2015). Incorporating Number of customers variable in the analysis provides a magnitude of the number of towns/villages as it reflects the total users in both villages and towns. The inclusion of both variables (number of customers and number of town/villages) as outputs is common in the literature (Pombo and Taborda, 2006; Yadav et al., 2011; Gouveia et al., 2015). Number of staff is an important input for service efficiency process which is also proposed in the relevant literature (Forsund and Kittelsen, 1998; Zhang and Bartels, 1998; Abbott, 2006; Cullman et al., 2008; Örkcü et al.,2015). Generally, electric distribution companies acquire capital (like machinery, buildings, transformers etc) for generation and distribution of electric power (Arcos-Vargas et al., 2017). To model the capital of each 
electric distribution company, variable length of cables is considered as input (Zhang and Bartels, 1998; Pahwa et al., 2002; Pombo and Taborda, 2006; Cullman and Hirschhausen, 2006; Cullman et al., 2008; Omrani et al., 2015; Gouveia et al., 2015; Örkcü et al.,2015). In the same context, number of transformers and installed capacity variables are considered as assets for electric power distribution process and are treated as inputs (Goto and Tsutsui, 1998; Zhang and Bartels, 1998; Pombo and Taborda, 2006; Omrani et al., 2015; Örkcü et al.,2015, Xie et al, 2018).

Recently, investigation of performance of electric distribution companies is very popular subject, especially for energy journals for developing countries. Zorzo et al. (2017) worked on efficiency of Brazilian Electric Distribution companies, and Ghasemi and Dashti (2017; 2018) studied electric distribution companies in Iran with a risk-based model. Mirza et al. (2017) investigated electric distribution companies' performance after major reforms since 1994. Also, Sartoti et al. (2017), examined the performance of Brazilian electrity power industry using Malmquist Index emphasizing on sustainability. Additionally, Şirin (2017) used panel data analysis to understand the factors affecting the costs of Turkish electric distribution companies between 2011 and 2014. Deng et al. (2018) worked on technical and service-quality efficiency of companies in China. Since raw materials are very significant for the electricity generation, the performance measurement should include raw materials as inputs (Welch and Barnum, 2017).

\section{-- TABLE 1 HERE --}

In this paper a new profit efficiency network DEA model-is proposed by using a new objective function and threshold value constraints as a modification of Directional Distance Function (DDF) Network DEA appreach. Since the analysis examines multiple stages with

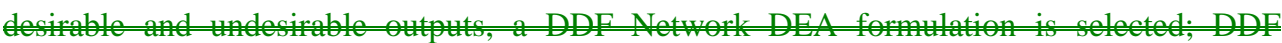
models consider simultaneously the maximization of a desirable output and the minimization 
ef an underible out for given inputs (Stohi \& Go, 2011). This DEA

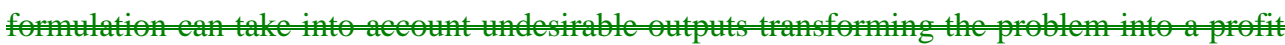
effieien model for meastring in order to increase efficiency, inputs should be decreased and outputs should be inereased. The contribution of the study lies also on the fact that the proposed model takes into account the expansion cost in the case where energy supply should be more than the eapabilities of a distion undesirable outputs respectively for profit efficiency of electric distribution companies measurement. From this aspect, although there are-several studies in the literature about efficiency evaluation of electric distribution companies, this stuly provides a first investigation of profit fficieney of electric distribution companies by using a nol appreach ef DEA DAl.

The next section presents the methodology of DDF Network DEA and two stage DEA model for profit efficiency. Section 3 presents the structure of two stage DEA process and inputs, outputs and undesirable outputs used in efficiency measurement applieation of Tukkish electric distribution companies. In Section 4 , the empirical results of proposed model are demenstrated. The study concludes in Section 5.

\section{Methodology}

\subsection{Nomenclature}

\begin{tabular}{||l|l|}
\hline Sets & Explanation \\
\hline$\dot{i}$ & Inputs \\
\hline$f_{t}$ & Undesirable outputs \\
\hline$f_{z}$ & Desirable outputs \\
\hline$K$ & Intermediate output \\
\hline$\dot{f}$ & DMUs \\
\hline Parameters & \\
\hline $\boldsymbol{x}_{i, j}$ & Input $i$ of DMU $j$ \\
\hline
\end{tabular}




\begin{tabular}{|c|c|}
\hline$y_{r_{1}, j}^{u}$ & Undesirable output $r_{t}$-of DMU $j$ \\
\hline$y_{r_{2}, j}^{a}$ & Desirable output $r_{z}$-of DMUj \\
\hline$y_{k, j}^{\mathrm{nnt}}$ & Intermediate output $k$ of $\mathrm{DMU} j$ \\
\hline$p_{r_{1}}$ & Price of desirable output $r_{t}$ \\
\hline$c_{r_{2}}$ & Cost of undesirable output $r_{z}$ \\
\hline$c_{i}$ & Cost of input $i$ \\
\hline E & Cost \\
\hline$R$ & Revenue \\
\hline \# & Profit \\
\hline$P E$ & Profit Efficiency \\
\hline \multicolumn{2}{|l|}{ Variables } \\
\hline$\lambda_{j}$ & Reference set of DMU $j$ \\
\hline$\beta$ & Level of inefficiency of each DMU $j$ \\
\hline$\lambda_{j}^{1}$ & Reference set of $1^{\text {st }}$ stage of $\mathrm{DMU} j$ \\
\hline$\lambda_{j}^{2}$ & Reference set of $2^{\mathrm{Ha}}$ stage of $\mathrm{DMU} j$ \\
\hline$\theta^{s \perp}$ & $\begin{array}{l}\text { Variable linking the efficiency between the } \\
\text { processes of } 1^{\text {st }} \text { and } 2^{\text {nd }} \text {-stage }\end{array}$ \\
\hline$\lambda_{j}^{1}$ & $\begin{array}{l}\text { Auxiliary variable for linearization of bilinear } \\
\text { term } \theta^{s 1} \cdot \sum_{j=1}^{n} \lambda_{j}^{1}\end{array}$ \\
\hline$\AA$ & $\begin{array}{l}\text { Binary variable associated with expansion } \\
\text { cest }\end{array}$ \\
\hline
\end{tabular}

Data Envelopment Analysis is a non parametric techique using mathematical programming that has been developed by Charnes et al (1978). It is used to measure the productivity of DMUs, separate them as efficient and inefficient units and evaluate their relative efficiency. Classical DEA models are classified according to their projections on inputs and outputs. In input oriented models, the models have an ability to project inputs' values of relevant DMU to become fully efficient. In other words, the models give target input values (for fixed output values) for the DMU under evalution. Similarly, in output oriented models, for fixed input values, the target outputs values can be estimated for the DMU under evalution. During the 
production process, a DMU (e.g. electric distiribution company) can generate undesirable outputs. This is a common problem when measuring efficiency of a certain type of industry such as electric power generation. The most commonly used method to handle this problem is the DDF method (Chung et al, 1997) since this technique allows a simultaneous reduction both on inputs and on undesirable outputs as well as an increase in the desirable outputs (Lozano et al., 2013).

In DEA, production process is generally considered as a single process which consumes a portion of inputs to produce final outputs. However, in the case where multiple stages are present in a system, the outputs of one stage is used as an intermidiate input for a subsequent stage. These types of systems can be expressed by two-stage production process and can be encountered in many sectors such as transportation, finance, energy and electricity etc. If there are more than one stage in production process of DMUs, DEA approach has to contain intermediate products. This type of DEA approaches are generally known as Network DEA. Electric generation and distribution industry is one of these types of industries which have multiple production stages. The productivity of electric distribution companies has been investigated throughly in the literature for different countries with several methods based on DEA, SFA, Malmquist Index etc. Furthermore, electric distribution companies aim to provide profit. Due to this fact, the inclusion of financial data to efficiency measurement of electric distribution companies, makes the analysis more realistic. All notations and indices are described and presented in Appendix as nomenclature part for the models in subsections of $\underline{\text { this section. }}$

\section{$\underline{3 z}$.1.}


Electric power production entails a series of processes. Several inputs and outputs have been identified in literature. Selection of variables for this study will be discussed in Section 3 . Using a Network DEA model with desirable and undesirable outputs, a detailed analysis can be conducted assessing the efficiency of each company. To that end, a Profit-Efficiency Network DEA model to evaluate the efficiency of each company based on the inputs and desirable/undesirable outputs, is proposed. In DEA model (1) it is assumed that there are $j$ DMUs consuming $x_{i, j}$ inputs and produce undesirable $\left(y_{r_{1}, j}^{u}\right)$ and desirable $\left(y_{r_{2}, j}^{d}\right)$ outputs. Variable $\beta$ is free and measures the level of inefficiency of each DMU $\boldsymbol{j}$. Finally, nonnegative variable $\lambda_{j}$ expresses the peers of DMU $j$. The technology of DEA model (1), is Variable Returns to Scale (VRS) based on constraint $\sum_{j=1}^{n} \lambda_{j}=1$.

$$
\max \beta
$$

s.t.

$$
\sum_{j=1}^{n} \lambda_{j} \cdot x_{i, j} \leq x_{i, j 0}, i=1, \ldots m
$$$$
\sum_{j=1}^{n} \lambda_{j} \cdot y_{r_{1}, j}^{u}=(1-\beta) \cdot y_{r 1, j 0}^{u}, r_{1}=1, \ldots, o_{1}
$$$$
\sum_{j=1}^{n} \lambda_{j} \cdot y_{r_{2}, j}^{d} \geq(1+\beta) \cdot y_{r 2, j 0}^{d}, r_{2}=1, \ldots, o_{2}
$$

$$
\sum_{j=1}^{n} \lambda_{j}=1
$$

$\lambda_{j} \geq 0, j=1, \ldots, n$

$$
\beta \text { free }
$$

The presented model (1) is introduced when there is a single production process as the one presented in Figure 1.

-- FIGURE 1 HERE--

\subsubsection{Two stage models for desirable and undesirable outputs}


In the case of two or more production processes, the model as presented in Figure 1 will change as the inputs are consumed in the first stage to produce outputs; either desirable or undesirable. Desirable outputs produced from the first production process (stage) are used as inputs for the next production process (stage). Graphically this procedure is presented in Figure 2.

\section{-- FIGURE 2 HERE--}

The DEA model that corresponds to Figure 2 is presented with formulation (2). As it can be seen in formulation (2), a new variable $\left(\theta^{s 1}\right)$ has been introduced to link the efficiency between the processes of $1^{\text {st }}$ and $2^{\text {nd }}$ stage. After Stage 1 process, two types of outputs are produced; desirable (intermediate) and undesirable. Assuming there are $p$ intermediate outputs and $O_{1}$ undesirable outputs denoted as $y_{k, j}^{\text {int }}$. The intermediate outputs from Stage 1 are used as inputs for the $2^{\text {nd }}$ Stage producing final $o_{2}$ outputs denoted with $y_{r 1, j}^{d}$. Also the two stages are connected with variables $\lambda_{j}^{1}$ and $\lambda_{j}^{2}$. 
s.t.

$\sum_{j=1}^{n} \lambda_{j}^{1} \cdot x_{i, j} \leq \theta^{s 1} \cdot x_{i, j 0}, i=1, \ldots m$

$\theta^{s 1} \cdot \sum_{j=1}^{n} \lambda_{j}^{1} \cdot y_{k, j}^{\mathrm{int}} \geq \sum_{j=1}^{n} \lambda_{j}^{2} \cdot y_{k, j}^{\mathrm{int}}, k=1, \ldots p$

$\theta^{s 1} \cdot \sum_{j=1}^{n} \lambda_{j}^{1} \cdot y_{r_{1}, j}^{u} \leq(1-\beta) \cdot y_{r 1, j 0}^{u}, r_{1}=1, \ldots, o_{1}$

$\sum_{j=1}^{n} \lambda_{j}^{2} \cdot y_{r_{2}, j}^{d} \geq(1+\beta) \cdot y_{r 2, j 0}^{d}, r_{2}=1, \ldots, o_{2}$

$\sum_{j=1}^{n} \lambda_{j}^{1}=1$

$\sum_{j=1}^{n} \lambda_{j}^{2}=1$

$0 \leq \theta^{s 1} \leq 1$

$\lambda_{j}^{1} \geq 0, j=1, \ldots, n$

$\lambda_{j}^{2} \geq 0, j=1, \ldots, n$

$\beta$ free

Due to the existence of bilinear terms (products of continuous variables) in formulation (2), DEA model is re-written as follows linearizing the non-linear terms $\left(\theta^{s 1} \cdot \sum_{j=1}^{n} \lambda_{j}^{1}\right)$. Based on formulation (3), bilinear term $\theta^{s 1} \cdot \sum_{j=1}^{n} \lambda_{j}^{1}$ has been replaced by variable $\hat{\lambda}_{j}^{1}$. Due to this reformulation, the following constraint is introduced $\sum_{j=1}^{n} \lambda_{j}^{1}=\theta^{s 1}$ for linearization of bilinear term. 


\subsubsection{Two stage model for Profit Efficiency}

Besides measuring the radial efficiency of each DMU $j$, the next Profit Efficiency Network DEA model is presented. In this case, objective function expresses profit based on inputsoutputs (desirable and undesirable).

Profit is defined as the difference of revenue and cost. Revenue function consists of the earnings of each company, business, firm etc. represented by each DMU by (4). In (4), revenue function consists of the sum product of price with the corresponding desirable $\left(p_{r_{1}}\right)$ for every DMU under investigation $j_{0}$. 
$R=\sum_{r_{1}} p_{r_{1}} \cdot y_{r_{1}, j_{0}}^{d}$

On the contrary, cost is presented in (5) and consists of the product of costs derived by inputs and undesirable outputs.

$$
C=\sum_{r_{2}} c_{r_{2}} \cdot y_{r_{2}, j_{0}}^{u}+\sum_{i=1}^{m} \sum_{j=1}^{n} c_{i} \cdot x_{i, j_{0}}
$$

$\Pi=R-C$

The DEA model for measuring Profit Efficiency for each DMU $j$ is presented in (7).

$$
\begin{aligned}
& \max \Pi=R-C= \\
& \sum_{r_{1}} p_{r_{1}} \cdot y_{r_{1}, j_{0}}^{d}-\sum_{r_{2}} c_{r_{2}} \cdot y_{r_{2}, j_{0}}^{u}+\sum_{i=1}^{m} \sum_{j=1}^{n} c_{i} \cdot x_{i, j_{0}} \\
& \text { s.t. } \\
& \sum_{j=1}^{n} \lambda_{j}^{1} \cdot x_{i, j} \leq x_{i, j 0}, i=1, \ldots m \\
& \sum_{j=1}^{n} \lambda_{j}^{1} \cdot y_{k, j}^{\mathrm{int}}=\sum_{j=1}^{n} \lambda_{j}^{2} \cdot y_{k, j}^{\mathrm{int}}, k=1, \ldots p \\
& \sum_{j=1}^{n} \lambda_{j}^{1} \cdot y_{r_{1}, j}^{u}=y_{r 1, j 0}^{u}, r_{1}=1, \ldots, o_{1} \\
& \sum_{j=1}^{n} \lambda_{j}^{2} \cdot y_{r_{2}, j}^{d} \geq y_{r 2, j 0}^{d}, r_{2}=1, \ldots, o_{2} \\
& \sum_{j=1}^{n} \lambda_{j}^{1}=1 \\
& \sum_{j=1}^{n} \lambda_{j}^{2}=1 \\
& \lambda_{j}^{1} \geq 0, j=1, \ldots, n \\
& \lambda_{j}^{2} \geq 0, j=1, \ldots, n
\end{aligned}
$$

To provide a realistic understanding of the process presented in the two stages (1 and 2) as shown in Figure 2, the impact of external factors should be taken into account in efficiency
Formatted: Font: $11 \mathrm{pt}$, English (United Kingdom), Do not check spelling or grammar

Field Code Changed

Formatted: Font: $11 \mathrm{pt}$, English (United Kingdom), Do not check spelling or grammar

Field Code Changed

Formatted: Font: $11 \mathrm{pt}$, English (United Kingdom), Do not check spelling or grammar Kingdom), Do not check spelling or grammar

Field Code Changed 
measurement. Based on this approach, a change (increase or decrease) in an output may have an impact on the objective function (revenue or cost). To measure that change in efficiency, additional constraints are introduced that link the changes that occur based on optimal values. Assuming that an output increases, at the excess that the recourses, infrastructures etc. allow to, then this increases cost based on a pre-determined set of constraints.

\section{Application}

In this section, an application of the proposed model is presented to 20 Turkish electric distribution companies with real data retrieved from TEIAŞ Annual Statistical Reports 2011. The companies have been anonoymized and given the code names E1-20. More specifically. companies E1, E2, E3 E5 and E19 serve Eastern Anatolian region, E4 and E20 serve Black Sea region, E6 and E17 serve Kiz1lirmak part of Anatolian region, E12 and E16 serve Thrace (Trakya) region, E10, E15 and E18 serve Aegean region, E7 and E9 serve Mediterranean region, E8 serves Anatolian region with E6 and E17. Furthermore, E11, E13 and E14 serve Marmara region of Turkey. -Data (inputs, intermediate, undesirable and final outputs), are represented in Table 24 . Two production processes (stages) are assumed. The first stage is associated with energy efficiency of each company. Inputs consist of number of staff (labour force), power that is used for energy production, installed capacity and to inputs that model the assets of each company (length of cables and number of transformers). The outputs of the $1^{\text {st }}$ stage is energy supplied while there are undesirable outputs derived from the $1^{\text {st }}$ stage (Annual faults and interruptions, Energy losses). The aforementioned characteristics concern energy efficiency but have an impact on customer satisfaction measured by the number of customers (household, industries etc) and number of towns/villages, that are served by each company.

\section{--TABLE 21 HERE--}


Applying input/output data to model (3), the following formulation is derived (8). In formulation (8), regarding the inputs, NSTAFF stands for the number of staff; NCONSM stands for net consumption, NTRANF stands for the number of transformers; LENGTHCABLES stands for the length of cables and INCAP for installed capacity. Intermediate output is only energy supply, denoted with ENSUPPLY. The undesirable outputs that are considered are ANFAULTS (annual faults and interruptions) and ENLOSSES (energy losses). Final outputs that model number of customers and towns/villages served by each company are denoted as NUMCUST and NUMToVill correspondingly. 
s.t.

$$
\begin{aligned}
& \sum_{j=1}^{n} \hat{\lambda}_{j}^{1} \cdot \operatorname{NSTAFF}_{j} \leq \theta^{s 1} \cdot \mathrm{NSTAFF}_{j_{0}} \\
& \sum_{j=1}^{n} \hat{\lambda}_{j}^{1} \cdot \operatorname{NCONSM}_{j} \leq \theta^{s 1} \cdot \operatorname{NCONSM}_{j_{0}}
\end{aligned}
$$$$
\sum_{j=1}^{n} \hat{\lambda}_{j}^{1} \cdot N T R A N S F_{j} \leq \theta^{s 1} \cdot N T R A N S F_{j_{0}}
$$$$
\sum_{j=1}^{n} \hat{\lambda}_{j}^{1} \cdot \text { LENGTHCABLES }_{j} \leq \theta^{s 1} \cdot \text { LENGTHCABLES }_{j_{0}}
$$$$
\sum_{j=1}^{n} \hat{\lambda}_{j}^{1} \cdot I N C A P_{j} \leq \theta^{s 1} \cdot I N C A P_{j_{0}}
$$$$
\sum_{j=1}^{n} \hat{\lambda}_{j}^{1} \cdot \operatorname{ENSUPPLY}_{j} \geq \sum_{j=1}^{n} \lambda_{j}^{2} \cdot \operatorname{ENSUPPLY}_{j}
$$$$
\sum_{j=1}^{n} \hat{\lambda}_{j}^{1} \cdot \text { ANFAULTS }_{j} \leq(1-\beta) \cdot \text { ANFAULTS }_{j_{0}}
$$$$
\sum_{j=1}^{n} \hat{\lambda}_{j}^{1} \cdot \text { ENLOSSES }_{j} \leq(1-\beta) \cdot \text { ENLOSSES }_{j_{0}}
$$

$$
\sum_{j=1}^{n} \lambda_{j}^{2} \cdot N U M C U S T_{j} \geq(1+\beta) \cdot N U M C U S T_{j_{0}}
$$$$
\sum_{j=1}^{n} \lambda_{j}^{2} \cdot \text { NUMToVill }_{j} \geq(1+\beta) \cdot \text { NUMToVill }_{j_{0}}
$$$$
\sum_{j=1}^{n} \hat{\lambda}_{j}^{1}=1
$$$$
\sum_{j=1}^{n} \lambda_{j}^{2}=1
$$$$
\sum_{j=1}^{n} \hat{\lambda}_{j}^{1}=\theta^{s 1}
$$

$\lambda_{j}^{1} \geq 0, j=1, \ldots, n$

$\lambda_{j}^{2} \geq 0, j=1, \ldots, n$

$\beta$ free

Profit Efficiency extraction is based on the same data (inputs and outputs) using formulation

(7). Expanded model (9) is described below. The objective function entails prices for energy 
supply (TL/MWh) denoted with $p^{1}$, average unit price per customer, as in this category there may be either households or industries that may be served by each company denoted with $p^{2}$ expressing (TL) and average price per town or village served denoted with $p^{3}$ expressed in (TL). Cost function consists of the costs that is associated with energy losses, expressed in lost sales denoted with $c^{1}$ (TL/MWh), the cost that is associated with a fixed value for each case that a fault may occur $c^{2}$ (TL) and labor cost (labc) expressed with (TL). 
s.t.

$$
\sum_{j=1}^{n} \lambda_{j}^{1} \cdot N S T A F F_{j} \leq N S T A F F_{j_{0}}
$$$$
\sum_{j=1}^{n} \lambda_{j}^{1} \cdot \operatorname{NCONSM}_{j} \leq \operatorname{NCONSM}_{j_{0}}
$$$$
\sum_{j=1}^{n} \lambda_{j}^{1} \cdot N T R A N S F_{j} \leq N T R A N S F_{j_{0}}
$$$$
\sum_{j=1}^{n} \lambda_{j}^{1} \cdot \text { LENGTHCABLES }_{j} \leq \text { LENGTHCABLES }_{j_{0}}
$$$$
\sum_{j=1}^{n} \lambda_{j}^{1} \cdot I N C A P_{j} \leq I N C A P_{j_{0}}
$$$$
\sum_{j=1}^{n} \lambda_{j}^{1} \cdot \text { ENSUPPLY }_{j} \geq \sum_{j=1}^{n} \lambda_{j}^{2} \cdot \operatorname{ENSUPPLY}_{j}
$$$$
\sum_{j=1}^{n} \lambda_{j}^{1} \cdot \operatorname{ANFAULTS}_{j}=\text { ANFAULTS }_{j_{0}}
$$

$\sum_{j=1}^{n} \lambda_{j}^{1} \cdot$ ENLOSSES $_{j}=$ ENLOSSES $_{j_{0}}$

$\sum_{j=1}^{n} \lambda_{j}^{2} \cdot N U M C U S T_{j} \geq N U M C U S T_{j_{0}}$

$\sum_{j=1}^{n} \lambda_{j}^{2} \cdot$ NUMToVill $_{j} \geq$ NUMToVill $_{j_{0}}$

$\sum_{j=1}^{n} \lambda_{j}^{1}=1$

$\sum_{j=1}^{n} \lambda_{j}^{2}=1$

$\lambda_{j}^{1} \geq 0, j=1, \ldots, n$

$\lambda_{j}^{2} \geq 0, j=1, \ldots, n$

Assuming that the projected value of a DMU, would suggest an extreme increase in energy supply (ENSUPPLY), then this increase could be achieved by expansion of capacity and additional cost in assets, capital, labor force etc. For example, if energy supply increases over a threshold ( ENSUPPLY $Y_{j}^{\text {threshold }}$ ), then an additional cost would have to be added to the overall 
cost of that specific company. Based on constraint (10), if left hand side that models the optimal value of DMU $j$ is more than ENSUPPLY $Y_{j}^{\text {threshold }}$ then binary variable $\Lambda$ yields a value of 1 , otherwise it provides a value of 0 .

$\sum_{j=1}^{n} \lambda_{j}^{1} \cdot \operatorname{ENSUPPLY}_{j} \geq \operatorname{ENSUPPLY}_{j_{0}}^{\text {threshold }} \cdot \Lambda$

This constraint is linked with objective function with the following additional term in objective function $\operatorname{Exp} C o s t \cdot \Lambda$; ExpCost expresses the expansion costs that company $j$ must invest, in order to provide the additional energy supply. The final DEA formulation is (11). The threshold that has been used in this instance is equal to the mean value of ENSUPPLY ${ }_{j}$. 

s.t.

$$
\sum_{j=1}^{n} \lambda_{j}^{1} \cdot N S T A F F_{j} \leq N S T A F F_{j_{0}}
$$$$
\sum_{j=1}^{n} \lambda_{j}^{1} \cdot \operatorname{NCONSM}_{j} \leq \operatorname{NCONSM}_{j_{0}}
$$$$
\sum_{j=1}^{n} \lambda_{j}^{1} \cdot N T R A N S F_{j} \leq N T R A N S F_{j_{0}}
$$$$
\sum_{j=1}^{n} \lambda_{j}^{1} \cdot \text { LENGTHCABLES }_{j} \leq \text { LENGTHCABLES }_{j_{0}}
$$$$
\sum_{j=1}^{n} \lambda_{j}^{1} \cdot I N C A P_{j} \leq I N C A P_{j_{0}}
$$$$
\sum_{j=1}^{n} \lambda_{j}^{1} \cdot \operatorname{ENSUPPLY}_{j} \geq \sum_{j=1}^{n} \lambda_{j}^{2} \cdot \operatorname{ENSUPPLY}_{j}
$$$$
\sum_{j=1}^{n} \lambda_{j}^{1} \cdot \text { ANFAULTS }_{j}=\text { ANFAULTS }_{j_{0}}
$$$$
\sum_{j=1}^{n} \lambda_{j}^{1} \cdot \text { ENLOSSES }_{j}=\text { ENLOSSES }_{j_{0}}
$$

$\sum_{j=1}^{n} \lambda_{j}^{2} \cdot N U M C U S T_{j} \geq N U M C U S T_{j_{0}}$

$\sum_{j=1}^{n} \lambda_{j}^{2} \cdot$ NUMToVill $_{j} \geq$ NUMToVill $_{j_{0}}$

$\sum_{j=1}^{n} \lambda_{j}^{1} \cdot \operatorname{ENSUPPLY}_{j} \geq \operatorname{ENSUPPLY}_{j_{0}}^{\text {threshold }} \cdot \Lambda$

$\sum_{j=1}^{n} \lambda_{j}^{1}=1$

$\sum_{j=1}^{n} \lambda_{j}^{2}=1$

$\lambda_{j}^{1} \geq 0, j=1, \ldots, n$

$\lambda_{j}^{2} \geq 0, j=1, \ldots, n$

$\Lambda \in\{0,1\}$ 


\section{Results}

\subsection{Efficiency based on radial measure}

In this section, the radial efficiency is extracted based on DEA model (8). The DEA model presented has been modeled and solved with GAMS, using CPLEX as LP solver. As it can be seen from Table $\underline{3} 2$, the companies that underperform are E8, E9, E10, E11, E12, E13, E14, E16, E17, E18, E19 and E20. The company with the largest percentage of inefficiency is E19 with $\beta=0.3397$ whereas the company with the lowest is $\mathrm{E} 9$ with $\beta=0.0334$.

\section{--TABLE $\underline{3}$ ? HERE--}

Due to limited data, one distribution company was excluded from the analysis. The remaining 20 companies constitute approximately $90 \%$ of market share in the sector. Efficient companies according to model (8) are E1, E2, E3, E4, E5, E6, E7 and E15. Efficiency based on radial measure consider as efficient the companies which are located especially in southeast region of Turkey. These companies are E1, E2, E3, E4, E5 and E6. And these companies demonstrate very frequency of annual faults and interrupts per customers as seen in Fig. 3.

\section{--FIGURE 3 HERE--}

As seen from Figure 3, the companies which have the high number of annual faults and interrupts per customers values are considered as efficient companies according to efficiency based radial measure model (8). It is known that unregistered subscribers are also fairly common in south-east region are of Turkey. By considering all these cases, these findings reduce the reliability of the efficiency results of radial measure model (8). 
To consider the reference sets results for inefficient companies, radial measures of model (8), optimal lambda (peers) values, are considered. The optimal lambda (peers) values $\left(\hat{\lambda}_{j}^{1, *}, \lambda_{j}^{2, *}\right)$ that are derived from model (8) are presented in the following tables (Tables $\underline{4} 3-\underline{5} 4)$ for each company (DMU).

\subsection{Efficiency based on profit efficiency}

In this section, the results of profit efficiency are reported. The resulting network DEA model (11) is formulated as Mixed Integer Linear Programming (MILP) model and has been solved using GAMS, using CPLEX as MILP solver. In Table $\underline{65}$, the Profit Efficiency (PE) is shown, whereas, $P E=\frac{\Pi^{*}}{\max \left\{\Pi^{*}\right\}}$. As it can be seen in Table $\underline{6} 5$, the largest value for profit efficiency is reported for company 16 . The lowest value has been reported for company E2 which is one of the efficient companies according to results of model (8). Based on model (11), additional capital for expansion in their infrastructure and for investments has been reported for companies E1, E7, E10, E11, E16.

\section{--TABLE 6 5 HERE--}

According to results in Table $\underline{6} 5$, E16 is only efficient company. Profit efficiency model decreased the number of efficient DMUs, thus it increased discrimination power. By taking into account profit and expansion cost idea in the objective function, it reflects more realistic result by making E16 efficient, which has very potential customers as house holders and 
industry, E16 has the highest electric suppy and amout of customers value in Turkey as seen in Figure 4 and Figure 5 .

\section{--FIGURE 4 HERE-- \\ --FIGURE 5 HERE--}

Company, E16 is the biggest electric distribution company in Turkey producing 19.184.186 MWh energy supply and 4.202.132 customers (as both householder and industry). The optimal lambda (peers) values $\left(\lambda_{j}^{1, *}, \lambda_{j}^{2, *}\right)$ that are derived from model (11) are presented in the Tables $\underline{7} 6$ and $\underline{8} 7$ for each company (DMU). By considering both Tables $\underline{4} z-\underline{5} 4$ and Tables $\underline{76}-\underline{8} 7$, the optimal lambda (peers) values results which are indicators for reference sets of both radial efficiency model and profit efficiency model are consistent with each other.

\section{--TABLE 76 HERE--}

--TABLE $\underline{8} 7$ HERE--

A comparison of the empirical cumulative density functions (ECDF) of the two types of efficiency (1- $\beta$ and $P E$ ) calculated based on models (8) and (11) respectively, is shown in Figure 6. With the use of ECDF plots, several conclusions can be drawn regarding the distribution of efficiency. The efficiency derived from model (8), does not have a high discrimination power as almost $60 \%$ of the DMUs have efficiency of 1 . This fact hinders the ranking of the units. On the contrary, based on the efficiency of model (11), only a single DMU has efficiency equal to 1 providing a clearer measure for ranking.

--FIGURE 6 HERE-- 
Besides examining the profit efficiency, other indices, can provide valuable information. Based on Figure 7, even if the largest value of profit is reported for company E16, in Profit/Customer index company E16 is ranked low. This profitability ratio can be balanced if there are imports of energy from one company to another, in case of energy deficiency caused by high demand. On the contrary, in the profitability index Profit/Asset, company E16 which has the highest profit, is ranked in a higher position while the highest position is reported for company E13. An information that is provided from this type of analysis is that E13 makes more efficient use of its assets, compared to any other company due to higher values of profit generated by more efficient use of its assets.

\section{--FIGURE 7 HERE--}

The proposed model measures, through a novel Network DEA model, the profit efficiency of distribution companies in Turkey. However, in order to further evaluate the qualitative and quantitative characteristics of the profit efficiency score for each distribution company, several comparisons should be made. Financial ratios, such as profit per customer, utilize information based on revenues and expenses providing conclusions based on purely economic and financial data. However, the profit efficiency as derived from the proposed model, defines profit as a function of multiple attributes and external factors that affect the underlying assumed production function. For sake of comparison and ranking construction of the distribution companies based on financial ratios and profit efficiency, several financial ratios are calculated.

More specifically, two indices are constructed, namely profitability ratio which is defined as the fraction of profits per customer and profitability index which is defined as the fraction of profits per asset. Both indices are compared with profit efficiency score as derived from the proposed Network DEA model. As shown in Figure 8 (a), the company with the largest profit 
efficiency is E16. However, distribution company E19 has higher values in the profit per customer ratio. Based on this index, E19 is more profitable compared to distribution company E16, even if both companies serve approximately equal number of customers (E16: 1,362,922, E19: 1,555,424). Nevertheless, in terms of the proposed Network DEA analysis, profit efficiency of distribution company E19 is quite low, leading to the conclusion that the profitability index may not lead to efficient operation and capital management. Besides the electric distribution companies that act as outliers in Figure 8 a), electric distribution companies E2, E12, have high values of profit per customer with low values of profit efficiency. Low values in profit efficiency lead to the conclusion that the aforementioned companies do not utilize efficiently their resources and there are opportunities to achieve higher profits. On the contrary, higher profit efficiency and medium profit per customer values are reported for distribution company E13. A straightforward conclusion is that this company makes better use of the available resources, as even if it serves 849.714 customers, which is significantly low compared to other distribution companies, the corresponding profit efficiency is quite high.

\section{--FIGURE 8 HERE--}

High profit values per customer index for distribution companies E1 and E14 are reported however, their corresponding profit efficiency values are medium. The same conclusion can be drawn regarding resource utilization with distribution company E13.

Regarding the profit per asset index electric distribution companies are compared with profit efficiency as derived from the proposed Network DEA model. From Figure $9 b$ ), it can be seen that electric distribution company E16 has the highest profit efficiency and the second largest value in profit per asset index. The highest value in profit per asset index i electric distribution company E13; the corresponding profit efficiency in percentage is $48.19 \%$ which 
is a medium value. The number of assets (number of transformers) of electric distribution company E13, is significantly low while the profit efficiency is quite high compared to other distribution companies. However, based on the fact that the profit efficiency is $48.19 \%$, this company does not make full use of its resources and can be improved with optimized resource utilization. The electric distribution company with the third higher profit per asset index is E10. This electric distribution company has a high profit efficiency score $(74.34 \%)$.

However, the comparison cannot provide special characteristics regarding the distribution of values of the financial indices (profit per customer and profit per asset) and the profit efficiency score. The 2-dimensional density estimation of profit per customer and profit efficiency is shown in Figure 9. More specifically, the points show the pairs of profit/customer and profit efficiency for each electric distribution company while the contours (isoquant lines) show the intensity of the distribution. It can be seen that the majority of the points are concentrated in the interval of less than $200 \mathrm{M}$ TL for profit efficiency (x-axis) and less than 100 TL for profit per customer index. This is an interesting finding as demonstrates that the majority of electric distribution companies demonstrate low values of profit efficiency and profit per customer using properly in most of the cases their resources.

\section{--FIGURE 9 HERE--}

The 2-dimensional density estimation of profit per asset and profit efficiency is shown in Figure 10. It can be seen that the majority of the points are concentrated in the interval of less than $100 \mathrm{M}$ TL for profit efficiency (x-axis) and less than $1000 \mathrm{TL}$ for profit per asset index.

--FIGURE 10 HERE-- 


\section{Discussion}

In this paper, a new model based on profit efficiency has been applied to electric sector in Turkey. Electric distribution companies is-alse an electrical power supplier for electrical transmission. From this aspect, they can be considered as a very crutial part of the electricity process and the profit can be a tool for them. Hence, electric distribution companies are the effective ones for whole electricity sector and taking them into account of profitability of the sector is a new aspect and original part of the research. Because of being a developing country and activity of privatizing policy in the sector, selecting of Turkey's electric distribution companies is also crutial point of the study. Additionally, the theory which is developed in this study could be applicable in any other industries and varied geographical locations.

Profit based objective function approach is a new idea in efficiency measurement process of electric distribution companies. The results are reliable and make sense for the problem at hand. Especially, the proposed model considered only one company as an efficient to clarify the best company in the sector and from this aspect, yielding a valuable discussion ability for researchers. In addition, when the scores of proposed model are ranked, it can be found that the some of the electric distribution companies have better performance than the others. These orders of efficiency are the result of a profit and cost-based approach underlying the model. The costs and profit values are specific currency values for Turkish electric distribution sector, and this point is the limitation of the model. The model can also be adapted to electric distribution sector of other countries by changing the coefficients in objective function and constraints. This issue can be considered as a scope of future researches and the model can be adapted to other countries. 
Measuring the performance of electric distribution companies provides valuable insight for a country level. An a-priori knowledge of performance of a company is important as the capacity of each company can be optimized due to exact knowledge of the resources. Based on the proposed network DEA model, the state can assess the performance of each electric distribution company and subsequently perform a series of actions regarding the improvement of their efficiency. A measure that can help towards this direction is to set a strict framework for reducing energy losses. Better quality management of the assets and capital of each company can potentially lead to less disruptions in the operations of each company, and eventually, to more profit.

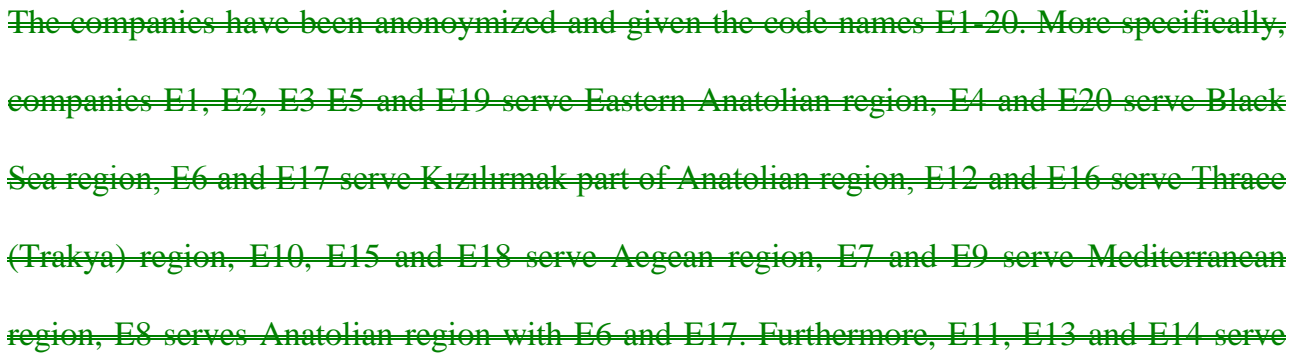
are located in the south part of Turkey concentrate high inefficiency and their efficiency scores are significantly lower than the companies in the west part of Turkey. Especially, the companies which are responsible from K1z1lırmak part of Anatolian region, eastern Anatolian region and south-eastern Anatolian region have very low efficiency scores in terms of profit efficiency. In eastern and central Black Sea region, the companies have also low profit efficiency values. Furthermore, it is noteworthy that there is a significant difference between efficiency scores of two distribution companies in Thrace (Trakya) region. The companies in Aegean region and Mediterranean region demonstrate better performance than other regions. According to the results, it can be suggested that, the precautions should be taken to reduce the amount of energy losses and illegal uses and increase the number of subscribers and 
customers in Kizılırmak part of Anatolian region, eastern Anatolian region and south-eastern Anatolian region. This can be achieved with competitive prices of high quality services. The companies that serve the coastal areas tend to capture this high quality.

\section{Conclusions}

Benchmarking of the electric distribution companies in the sector has become a subject that is studied widely nowadays due to the effect of privatization policies for developing countries. Several studies have been proposed for efficiency evaluation of electric distribution companies in various countries around the world. The common feature of these studies is performance measurement using the relative efficiency of companies using DEA, SFA, Malmquist Index by considering the variables related with the electricity distribution. In this paper Network DEA methodology has been employed which reflects realistically the measurement of productivity of systems or sectors that have intermediate products which are outputs from one process and are used as inputs for another procedds. In this paper a new profit efficiency network DEA model by using a new objective function and threshold value in constraint as a modification of Directional Distance Function (DDF) network DEA approach is proposed. The proposed model provides the ability to take incorporate undesirable outputs and reflects prices and profits in electricity sector. Undesirable output and prices-profit models take into consideration the efficiency measurement process of electric distribution companies. The proposed model aims to measure the efficiency of Turkish electric distribution companies by proposing a new model by taking into account profit efficiency and expansion cost at the same time in Network DEA. From this aspect, the proposed model help to develop a policy for practitioners by considering more realible results. The models that have been used in this paper utilise radial efficiency and profit 
effiency. The latter model (profit efficiency) has been modified in order to take into account external effects to DMUs. More specifically, for each DMU examined, a new set of constraint has been introduced in order to analyse whether the specific DMU exceeds a predefined threshold; if so, a cost is associated with the DMU (electric distribution company), on the basis of an expansion cost. Regarding radial efficiency measure model 8 electric distribution companies were found to be efficient, and are the following: E1-7 and E15 . On the contrary, according to results, the proposed model gives more realistic results than radial efficiency model in the literature. The proposed model is modified in order to increase the discrimination power by considering only E16 as efficient company, which is the largest electric distribution company in Turkey, in the terms of total number of customers and Energy supply (MWh) variables which are outputs of second and first stage of Network DEA.

The results of the proposed model makes sense and reflect the situation of electric production of Turkey. The proposed model, incorporates companies' profits, since profit as an index constitute an important indicator for such companies in the sector. Thus, based on the aforementioned, the results of proposed model are more helpful for practitioners and policy makers in the sector. The novel Network DEA methodology can be considered as an alternative reliable tool to measure the efficiencies in energy sector to reach to the betterquality management.

According to the results, E16 is the best company, thus it can be considered as a locomotive company in electric distribution sector in the terms of management and organization. In other words, it is a guidance company for others. Furthermore, the companies which are located in the south part of Turkey concentrate high inefficiency and their efficiency scores are significantly lower than the companies in the west part of Turkey. As a novelty part of this paper, the proposed model measures the efficiency of electric distribution companies by 
taking into account profit and expansion cost in Network DEA. From this aspect, the proposed model help to measure all of these crutial elements of the sector at the same time. At this point, the proposed model help to look from a new aspect for practitioners.

\section{References}

1. Abbott, M. (2006). The productivity and efficiency of the Australian electricity supply industry, Energy Economics, 28, 444-454.

2. Annual Report of Ministry of Energy and Natural Resources, Ankara, Turkey; 2011. http://www.tedas.gov.tr/sx.web.docs/tedas/docs/faaliyetrapor//Tr_Web_Versiyon_Ted as_2011_Faaliyet_raporu.pdf

3. Arcos-Vargas, A., Núñez-Hernández, F., \& Villa-Caro, G. (2017). A DEA analysis of electricity distribution in Spain: An industrial policy recommendation. Energy Policy, 102, 583-592.

4. Bagdadioglu, N., Price, C. M. W., \& Weyman-Jones, T. G. (1996). Efficiency and ownership in electricity distribution: a non-parametric model of the Turkish experience. Energy Economics, 18(1-2), 1-23.

5. Bagdadioglu, N., Basaran, A., Price, C.M.W. (2007). Potential impact of electricity reforms on Turkish households. University of East Anglia ESRC Centre for Competition Policy and Norwich Business School, CCP Working Paper No. 07-8.

6. Charnes, A., Cooper, W. W., \& Rhodes, E. (1978). Measuring the efficiency of decision making units. European journal of operational research, 2(6), 429-444.

7. Chung, Y. H., Färe, R., \& Grosskopf, S. (1997). Productivity and undesirable outputs: a directional distance function approach.journal of Environmental 
Management, 51(3), 229-240. Competition Policy and Norwich Business School, CCP Working Paper No. 07-8.

8. Colak, I., Bayindir, R., Fulli, G.,Tekin, I., Demirtas, K., Covrig, C., (2014) Smart grid opportunities and applications in Turkey, Renewable and Sustainable Energy Reviews $33: 344-352$.

9. Cullman, A., Hirschhausen, C. (2006). Efficiency analysis of East European electricity distribution in transition: legacy of the past? Journal of Productivity Analysis, 29:155-167.

10. Cullman, A., Crespo, H., Plagnet, M.A. (2008). International Benchmarking in Electricity Distribution: A Comparison of French and German Utilities. German Institute for Economic Research Discussion Paper, 830: 1-27.

11. Deng, N. Q., Liu, L. Q., \& Deng, Y. Z. (2017). Estimating the effects of restructuring on the technical and service-quality efficiency of electricity companies in China. Utilities Policy.

12. Edvardsen, D.F., Forsund, F.R. (2003). International benchmarking of electricity distribution utilities. Resource and Energy Economics, 25, 353-371.

13. Filippini, M., \& Wetzel, H. (2014). The impact of ownership unbundling on cost efficiency: Empirical evidence from the New Zealand electricity distribution sector. Energy economics, 45, 412-418.

14. Forsund, F.R., Kittelsen, S.A.C. (1998). Productivity development of Norwegian electricity distribution utilities. Resource and Energy Economics, 20, 207-224.

15. Giannakis, D., Jamasb, T., Pollitt, M. (2005). Benchmarking and incentive regulation of quality of service: An application to the UK electricity distribution networks. Energy Policy, 33, 2256-2271. 
16. Ghasemi, M., \& Dashti, R. (2017). A risk-based model for performance-based regulation of electricity distribution companies. Utilities Policy, 45, 36-44.

17. Goto, M., Tsutsui, M. (1998). Comparison of Productive and Cost Effciencies Among Japanese and US Electric Utilities”, International Journal of Management Science, 26 (2), 177-194.

18. Gouveia, M. C., Dias, L. C., Antunes, C. H., Boucinha, J., \& Inácio, C. F. (2015). Benchmarking of maintenance and outage repair in an electricity distribution company using the value-based DEA method. Omega, 53, 104-114.

19. Hess, B., Cullman A. (2007). Efficiency analysis of East and West German electricity distribution companies - Do the "Ossis" really beat the "Wessis"? Utilities Policy, 15, 206-214.

20. Jamasb, T., Pollitt, M. (2003). International benchmarking and regulation: An application to European electricity distribution utilities. Energy Policy, 31, 16091622.

21. Korhonen, P.J., Syrjanen, M.J. (2003). Evaluation of cost efficiency in Finnish electricity distribution. Annals of Operations Research, 121, 105-122.

22. Lozano, S., Gutiérrez, E., \& Moreno, P. (2013). Network DEA approach to airports performance assessment considering undesirable outputs. Applied Mathematical Modelling, 37(4), 1665-1676.

23. Mirza, F. M., Mushtaq, I., \& Ullah, K. (2017). Assessing the efficiency dynamics of post reforms electricity distribution utilities in Pakistan. Utilities Policy, 47, 18-28.

24. Omrani, H., Beiragh, R. G., \& Kaleibari, S. S. (2015). Performance assessment of Iranian electricity distribution companies by an integrated cooperative game data envelopment analysis principal component analysis approach. International Journal of Electrical Power \& Energy Systems, 64, 617-625.

25. Official Newspaper of Republic of Turkey, No: 25422, Ankara, Turkey; 2004. http://www.resmigazete.gov.tr/eskiler/2004/04/20040403.html 
26. Örkcü, H.H., Unsal, M.G., Bal, H., "A modification of a mixed integer linearprogramming (MILP) model to avoid the computational complexity”, Annals of Operations Research, 235 (1), 599-623, 2015.

27. Pahwa, A., Feng, X., Lubkeman, D. (2002). Performance evaluation of electricity distribution utilities based on data envelopment analysis. IEEE Transactions on Power Systems, 17, 400-405.

28. Pombo, C., Taborda, R. (2006). Performance and efficiency in Colombia's power distribution system: Effects of the 1994 reform. Energy Economics, 28, 339-369.

29. Retzlaff-Roberts, D. L. (1996). Relating discriminant analysis and data envelopment analysis to one another. Computers \& operations research, 23(4), 311-322.

30. Souza, M.V., Diallo, M., Souza, R.C., Baidya, T.K. (2010). The Cost Efficiency of the Brazilian Electricity Distribution Utilities: A Comparison of Bayesian SFA and DEA Models. Hindawi Publishing Corporation Mathematical Problems in Engineering Volume, Article ID 593059, 20 pages.

31. Sartori, S., Witjes, S., \& Campos, L. M. (2017). Sustainability performance for Brazilian electricity power industry: An assessment integrating social, economic and environmental issues. Energy Policy, 111, 41-51.

32. Sueyoshi, T., \& Goto, M. (2011). DEA approach for unified efficiency measurement: assessment of Japanese fossil fuel power generation. Energy Economics, 33(2), 292303.

33. Sueyoshi, T., \& Goto, M. (2016). Undesirable congestion under natural disposability and desirable congestion under managerial disposability in US electric power industry measured by DEA environmental assessment. Energy Economics, 55, 173-188.

34. Turkish Electricity Transmission Company (TETC). Turkey Electricity Statistic 2011, Ankara, Turkey; 2012. 
http://www.teias.gov.tr/TürkiyeElektrikİstatistikleri/istatistik2010/İstatistik\%202010. html.

35. Welch, E., \& Barnum, D. (2009). Joint environmental and cost efficiency analysis of electricity generation. Ecological Economics, 68(8-9), 2336-2343.

36. Xie, B. C., Gao, J., Chen, Y. F., \& Deng, N. Q. (2018). Measuring the efficiency of grid companies in China: A bootstrapping non-parametric meta-frontier approach. Journal of Cleaner Production, 174, 1381-1391.

37. Yadav, V. K., Padhy, N. P., \& Gupta, H. O. (2011). Performance evaluation and improvement directions for an Indian electric utility. Energy policy, 39(11), 71127120.

38. Yunos, J.M., Hawdon, D. (1997). The efficiency of the National Electricity Board in Malaysia: An intercountry comparison using DEA. Energy Economics, 19, 255-269.

39. Zhang, Y., Bartels, B. (1998). The effect of sample size on the mean efficiency in DEA with an application to electricity distribution in Australia, Sweden and New Zealand. Journal of Productivity Analysis, 9, 187-204.

40. Zorzo, L. S., Diehl, C. A., Venturini, J. C., \& Zambon, E. P. (2017). The relationship between the focus on innovation and economic efficiency: a study on Brazilian electric power distribution companies. RAI Revista de Administração $e$ Inovação, 14(3), 235-249. 


\title{
A novel network data envelopment analysis model for performance measurement of Turkish electric distribution companies
}

\author{
Konstantinos Petridis ${ }^{\mathrm{a}}$,,Mehmet Güray Ünsal ${ }^{\mathrm{b}}$, Prasanta Dey ${ }^{\mathrm{c},}{ }^{*}$, Hasan H. Örkcï ${ }^{\mathrm{d}}$ \\ ${ }^{a}$ Department of Applied Informatics, 156 Egnatia str., 54006, Thessaloniki, Greece \\ ${ }^{\mathrm{b}}$ Department of Statistics, Art and Science Faculty, Uşak University, Main Campus, Uşak, \\ Turkey \\ ${ }^{c}$ Operations and Information Management, Aston Business School, Aston University, \\ Birmingham, UK \\ ${ }^{\mathrm{d}}$ Department of Statistics, Science Faculty, Gazi University, Teknikokullar Beşevler, Ankara, \\ Turkey
}

\footnotetext{
*Corresponding author, e-mail: k.petridis@ uom.edu.gr, Tel: +30 2310891728
} 


\section{Abstract}

Electric distribution companies have a significant role for both households and industries. Benchmarking of the electric distribution companies in the energy sector has become a subject that is studied widely nowadays due to the effect of privatization policies for developing countries. Since there are multiple production stages regarding the generation and supply procedures of electric power, Network DEA technique is used. Directional Distance Function is also integrated into Network DEA technique. Electric distribution companies are organizations that are aiming at maximizing profit while minimizing the expenses. The main problem is how the profit idea can be integrated into the evaluation process. The aim of the proposed model is to evaluate profit efficiency of electric distribution companies while taking into account expansion cost for additional energy supply. This two stage approach is applied to Turkish electric distribution companies. Results are presented based on radial and profit efficiency measures. The proposed model is demonstrates realistic results by considering the expenses and incomes of distribution companies.

Keywords: Network DEA, Profit efficiency, Directional Distance Function, Electric Distribution

JEL Classification: C6, Q4 


\section{Introduction}

Aiming to liberalize the distribution sector in Turkey, privatization in electric distribution sector started in 2004 and completed in 2010, within the legislation framework of Electricity Market Law and according to the Privatization High Council decree no. 2004/22, dated April 02, 2004 (Official Newspaper of Republic of Turkey, No: 25422, Ankara, Turkey; 2004). In 1994, TEİAŞ (Turkey Electric distribution companies Corporation) started to operate officially with the aim of reaching optimum productivity and maximum profitability in services; TEİAŞ is responsible for supplying electrical energy to the customers from large cities to small residential areas (TEİAŞ Annual Statistical Reports, 2011). Various projects were completed or were in progress to evaluate and assist management, planning and operations of electric power distribution. Besides these operational projects, statistics related to electricity distribution and annual reports were included in publications (TEİAŞ Annual Statistical Reports, 2011; Colak et al., 2014). Furthermore, several numerical data analyses were conducted to evaluate service or distribution performance of electric distribution companies worldwide. Some of these analyses are based on statistical and operational research techniques such as Data Envelopment Analysis (DEA), Stochastic Frontier Analysis (SFA), Malmquist Index, Ordinary Least Squares (OLS) etc.

The first study related to electric distribution companies in Turkey has been investigated by Bagdadioglu et al. (1996). Their study presented a comparison of technical efficiency between public and private electric distribution companies to examine the effect of privatization of electric distribution companies in Turkey. Based on the findings of this study, high performance state-owned electric distribution companies were separated to be privatized. The efficiency analysis of Turkish electric distribution companies has been 
examined, considering number of staffs, operational expenditures as inputs and number of customers, total energy supply as outputs (Örkcü et al., 2015).

In this paper a new profit efficiency network DEA model is proposed by using a new objective function and threshold value constraints as a modification of Directional Distance Function (DDF) Network DEA approach. Since the analysis examines multiple stages with desirable and undesirable outputs, a DDF Network DEA formulation is selected; DDF models consider simultaneously the maximization of a desirable output and the minimization of an undesirable output for given inputs (Sueyoshi \& Goto, 2011). This novel DEA formulation can take into account undesirable outputs transforming the problem into a profit efficiency model for measuring electric production efficiency. Most DEA models assume that in order to increase efficiency, inputs should be decreased and outputs should be increased. The contribution of the study lies also on the fact that the proposed model takes into account the expansion cost in the case where energy supply should be more than the capabilities of a distribution company. Revenue and cost functions are construced based on desirable and undesirable outputs respectively for profit efficiency of electric distribution companies measurement. From this aspect, although there are several studies in the literature about efficiency evaluation of electric distribution companies, this study provides a first investigation of profit efficiency of electric distribution companies by using a novel approach of Network DEA model.

The next sections present the literature survey and common used variables in electric distribution sector and methodology of DDF Network DEA and two stage DEA model for profit efficiency, respectively. Section 4 presents the structure of two stage DEA process and 


\section{Common Used Variables in Literaturev Survey of Electric Distribution Sector Efficiency}

Data Envelopment Analysis (DEA) uses input(s) and output(s) variables in the efficiency measurement process. According to Retzlaff-Roberts (1996), it is suggested that the concept of positive and negative effective variables method is preferred to the classical concept of input and output variables. According to his study, the variables where an increase is reported provide better evaluation of the unit and these variables are considered as positive effective variables. This idea of Retzlaff-Roberts (1996) and the studies in the literature about measuring the performance of electric distribution companies will be guide in the variable selection process for this study.

By considering both the concept of Retzlaff-Roberts (1996) and the studies in the literature about measuring the performance of electric distribution companies, some generalizations can be made about which variables/indicators should be used as inputs or outputs in performance measurement process of electric distribution companies. Total energy supply data is defined as the sum of net consumption and energy losses. Energy supply is an output in electricity distribution process for electric distribution companies (Yunos and Hawdon, 1997; Forsund and Kittelsen, 1998; Korhonen and Syrjanen, 2003; Edvardsen and Forsund, 2003; Giannakis et al., 2005; Hess and Cullman, 2007; Bagdadioglu et al., 2007; Souza et al., 2010). In relevant studies, Net consumption variable is treated as input for assessing efficiency of electric distribution companies. Energy losses variable is widely used for this kind of efficiency measurement studies as seen from the studies in literature (Forsund and Kittelsen, 1998; Pahwa et al., 2002; Jamasb and Pollitt, 2003; Edvardsen and Forsund, 2003). 
Nevertheless, energy losses variable has a negative sign and can be considered as an 
Recently, investigation of performance of electric distribution companies is very popular subject for developing countries. Zorzo et al. (2017) worked on efficiency of Brazilian Electric Distribution companies, and Ghasemi and Dashti $(2017$; 2018) studied electric distribution companies in Iran with a risk-based model. Mirza et al. (2017) investigated electric distribution companies' performance after major reforms since 1994. Also, Sartoti et al. (2017), examined the performance of Brazilian electrity power industry using Malmquist Index emphasizing on sustainability. Additionally, Şirin (2017) used panel data analysis to understand the factors affecting the costs of Turkish electric distribution companies between 2011 and 2014. Deng et al. (2018) worked on technical and service-quality efficiency of companies in China. Since raw materials are very significant for the electricity generation, the performance measurement should include raw materials as inputs (Welch and Barnum, 2017).

\section{-- TABLE 1 HERE --}

\section{Methodology}

Data Envelopment Analysis is a non parametric techique using mathematical programming that has been developed by Charnes et al (1978). It is used to measure the productivity of DMUs, separate them as efficient and inefficient units and evaluate their relative efficiency. Classical DEA models are classified according to their projections on inputs and outputs. In input oriented models, the models have an ability to project inputs' values of relevant DMU to become fully efficient. In other words, the models give target input values (for fixed output values) for the DMU under evalution. Similarly, in output oriented models, for fixed input values, the target outputs values can be estimated for the DMU under evalution. During the production process, a DMU (e.g. electric distiribution company) can generate undesirable outputs. This is a common problem when measuring efficiency of a certain type of industry such as electric power generation. The most commonly used method to handle this problem is 
the DDF method (Chung et al, 1997) since this technique allows a simultaneous reduction both on inputs and on undesirable outputs as well as an increase in the desirable outputs (Lozano et al., 2013).

In DEA, production process is generally considered as a single process which consumes a portion of inputs to produce final outputs. However, in the case where multiple stages are present in a system, the outputs of one stage is used as an intermidiate input for a subsequent stage. These types of systems can be expressed by two-stage production process and can be encountered in many sectors such as transportation, finance, energy and electricity etc. If there are more than one stage in production process of DMUs, DEA approach has to contain intermediate products. This type of DEA approaches are generally known as Network DEA. Electric generation and distribution industry is one of these types of industries which have multiple production stages. The productivity of electric distribution companies has been investigated throughly in the literature for different countries with several methods based on DEA, SFA, Malmquist Index etc. Furthermore, electric distribution companies aim to provide profit. Due to this fact, the inclusion of financial data to efficiency measurement of electric distribution companies, makes the analysis more realistic. All notations and indices are described and presented in Appendix as nomenclature part for the models in subsections of this section.

\subsection{Modelling desirable and undesirable outputs}

Electric power production entails a series of processes. Several inputs and outputs have been identified in literature. Selection of variables for this study will be discussed in Section 3. Using a Network DEA model with desirable and undesirable outputs, a detailed analysis can be conducted assessing the efficiency of each company. To that end, a Profit-Efficiency Network DEA model to evaluate the efficiency of each company based on the inputs and 
desirable/undesirable outputs, is proposed. In DEA model (1) it is assumed that there are $j$ DMUs consuming $x_{i, j}$ inputs and produce undesirable $\left(y_{r_{1}, j}^{u}\right)$ and desirable $\left(y_{r_{2}, j}^{d}\right)$ outputs. Variable $\beta$ is free and measures the level of inefficiency of each DMU $j$. Finally, nonnegative variable $\lambda_{j}$ expresses the peers of DMU $j$. The technology of DEA model (1), is Variable Returns to Scale (VRS) based on constraint $\sum_{j=1}^{n} \lambda_{j}=1$.

$$
\begin{aligned}
& \max \beta \\
& \text { s.t. } \\
& \sum_{j=1}^{n} \lambda_{j} \cdot x_{i, j} \leq x_{i, j 0}, i=1, \ldots m \\
& \sum_{j=1}^{n} \lambda_{j} \cdot y_{r_{1}, j}^{u}=(1-\beta) \cdot y_{r 1, j 0}^{u}, r_{1}=1, \ldots, o_{1} \\
& \sum_{j=1}^{n} \lambda_{j} \cdot y_{r_{2}, j}^{d} \geq(1+\beta) \cdot y_{r 2, j 0}^{d}, r_{2}=1, \ldots, o_{2} \\
& \sum_{j=1}^{n} \lambda_{j}=1 \\
& \quad \lambda_{j} \geq 0, j=1, \ldots, n \\
& \quad \beta \text { free }
\end{aligned}
$$

The presented model (1) is introduced when there is a single production process as the one presented in Figure 1.

\section{-- FIGURE 1 HERE--}

\subsection{Two stage models for desirable and undesirable outputs}

In the case of two or more production processes, the model as presented in Figure 1 will change as the inputs are consumed in the first stage to produce outputs; either desirable or undesirable. Desirable outputs produced from the first production process (stage) are used as inputs for the next production process (stage). Graphically this procedure is presented in Figure 2. 


\section{-- FIGURE 2 HERE--}

The DEA model that corresponds to Figure 2 is presented with formulation (2). As it can be seen in formulation (2), a new variable $\left(\theta^{s 1}\right)$ has been introduced to link the efficiency between the processes of $1^{\text {st }}$ and $2^{\text {nd }}$ stage. After Stage 1 process, two types of outputs are produced; desirable (intermediate) and undesirable. Assuming there are $p$ intermediate outputs and $o_{1}$ undesirable outputs denoted as $y_{k, j}^{\text {int }}$. The intermediate outputs from Stage 1 are used as inputs for the $2^{\text {nd }}$ Stage producing final $O_{2}$ outputs denoted with $y_{r 1, j}^{d}$. Also the two stages are connected with variables $\lambda_{j}^{1}$ and $\lambda_{j}^{2}$.

$$
\begin{aligned}
& \max \beta \\
& \text { s.t. } \\
& \sum_{j=1}^{n} \lambda_{j}^{1} \cdot x_{i, j} \leq \theta^{s 1} \cdot x_{i, j 0}, i=1, \ldots m \\
& \theta^{s 1} \cdot \sum_{j=1}^{n} \lambda_{j}^{1} \cdot y_{k, j}^{\mathrm{int}} \geq \sum_{j=1}^{n} \lambda_{j}^{2} \cdot y_{k, j}^{\mathrm{int}}, k=1, \ldots p \\
& \theta^{s 1} \cdot \sum_{j=1}^{n} \lambda_{j}^{1} \cdot y_{r_{1}, j}^{u} \leq(1-\beta) \cdot y_{r 1, j 0}^{u}, r_{1}=1, \ldots, o_{1} \\
& \sum_{j=1}^{n} \lambda_{j}^{2} \cdot y_{r_{2}, j}^{d} \geq(1+\beta) \cdot y_{r 2, j 0}^{d}, r_{2}=1, \ldots, o_{2} \\
& \sum_{j=1}^{n} \lambda_{j}^{1}=1 \\
& \sum_{j=1}^{n} \lambda_{j}^{2}=1 \\
& 0 \leq \theta^{s 1} \leq 1 \\
& \lambda_{j}^{1} \geq 0, j=1, \ldots, n \\
& \lambda_{j}^{2} \geq 0, j=1, \ldots, n \\
& \beta \text { free }
\end{aligned}
$$

Due to the existence of bilinear terms (products of continuous variables) in formulation (2), DEA model is re-written as follows linearizing the non-linear terms $\left(\theta^{s 1} \cdot \sum_{j=1}^{n} \lambda_{j}^{1}\right)$. Based on 
formulation (3), bilinear term $\theta^{s 1} \cdot \sum_{j=1}^{n} \lambda_{j}^{1}$ has been replaced by variable $\hat{\lambda}_{j}^{1}$. Due to this reformulation, the following constraint is introduced $\sum_{j=1}^{n} \lambda_{j}^{1}=\theta^{s 1}$ for linearization of bilinear term.

$$
\begin{aligned}
& \max \beta \\
& \text { s.t. } \\
& \sum_{j=1}^{n} \hat{\lambda}_{j}^{1} \cdot x_{i, j} \leq \theta^{s 1} \cdot x_{i, j 0}, i=1, \ldots m \\
& \sum_{j=1}^{n} \hat{\lambda}_{j}^{1} \cdot y_{k, j}^{\mathrm{int}} \geq \sum_{j=1}^{n} \lambda_{j}^{2} \cdot y_{k, j}^{\mathrm{int}}, k=1, \ldots p \\
& \sum_{j=1}^{n} \hat{\lambda}_{j}^{1} \cdot y_{r_{1}, j}^{u} \leq(1-\beta) \cdot y_{r 1, j 0}^{u}, r_{1}=1, \ldots, o_{1} \\
& \sum_{j=1}^{n} \lambda_{j}^{2} \cdot y_{r_{2}, j}^{d} \geq(1+\beta) \cdot y_{r 2, j 0}^{d}, r_{2}=1, \ldots, o_{2} \\
& \sum_{j=1}^{n} \hat{\lambda}_{j}^{1}=1 \\
& \sum_{j=1}^{n} \lambda_{j}^{2}=1 \\
& \sum_{j=1}^{n} \hat{\lambda}_{j}^{1}=\theta^{s 1} \\
& \hat{\lambda}_{j}^{1} \geq 0, j=1, \ldots, n \\
& \lambda_{j}^{2} \geq 0, j=1, \ldots, n \\
& \beta \text { free }
\end{aligned}
$$

\subsection{Two stage model for Profit Efficiency}

Besides measuring the radial efficiency of each DMU $\boldsymbol{j}$, the next Profit Efficiency Network DEA model is presented. In this case, objective function expresses profit based on inputsoutputs (desirable and undesirable). 
Profit is defined as the difference of revenue and cost. Revenue function consists of the earnings of each company, business, firm etc. represented by each DMU by (4). In (4), revenue function consists of the sum product of price with the corresponding desirable $\left(p_{r_{1}}\right)$ for every DMU under investigation $j_{0}$.

$$
R=\sum_{r_{1}} p_{r_{1}} \cdot y_{r_{1}, j_{0}}^{d}
$$

On the contrary, cost is presented in (5) and consists of the product of costs derived by inputs and undesirable outputs.

$$
C=\sum_{r_{2}} c_{r_{2}} \cdot y_{r_{2}, j_{0}}^{u}+\sum_{i=1}^{m} \sum_{j=1}^{n} c_{i} \cdot x_{i, j_{0}}
$$

Profit $(\Pi)$ is defined as the difference between revenue and cost for each

$$
\Pi=R-C
$$

The DEA model for measuring Profit Efficiency for each DMU $j$ is presented in (7). 
$\max \Pi=R-C=$

$$
\sum_{j=1}^{n} \lambda_{j}^{2} \cdot y_{r_{2}, j}^{d} \geq y_{r 2, j 0}^{d}, r_{2}=1, \ldots, o_{2}
$$$$
\sum_{j=1}^{n} \lambda_{j}^{1}=1
$$$$
\sum_{j=1}^{n} \lambda_{j}^{2}=1
$$$$
\lambda_{j}^{1} \geq 0, j=1, \ldots, n
$$$$
\lambda_{j}^{2} \geq 0, j=1, \ldots, n
$$

To provide a realistic understanding of the process presented in the two stages (1 and 2) as shown in Figure 2, the impact of external factors should be taken into account in efficiency measurement. Based on this approach, a change (increase or decrease) in an output may have an impact on the objective function (revenue or cost). To measure that change in efficiency, additional constraints are introduced that link the changes that occur based on optimal values. Assuming that an output increases, at the excess that the recourses, infrastructures etc. allow to, then this increases cost based on a pre-determined set of constraints.

\section{Application}

In this section, an application of the proposed model is presented to 20 Turkish electric distribution companies with real data retrieved from TEİŞ̧ Annual Statistical Reports 2011. The companies have been anonoymized and given the code names E1-20. More specifically, companies E1, E2, E3 E5 and E19 serve Eastern Anatolian region, E4 and E20 serve Black 
Sea region, E6 and E17 serve Kizılırmak part of Anatolian region, E12 and E16 serve Thrace (Trakya) region, E10, E15 and E18 serve Aegean region, E7 and E9 serve Mediterranean region, E8 serves Anatolian region with E6 and E17. Furthermore, E11, E13 and E14 serve Marmara region of Turkey. Data (inputs, intermediate, undesirable and final outputs), are represented in Table 2. Two production processes (stages) are assumed. The first stage is associated with energy efficiency of each company. Inputs consist of number of staff (labour force), power that is used for energy production, installed capacity and to inputs that model the assets of each company (length of cables and number of transformers). The outputs of the $1^{\text {st }}$ stage is energy supplied while there are undesirable outputs derived from the $1^{\text {st }}$ stage (Annual faults and interruptions, Energy losses). The aforementioned characteristics concern energy efficiency but have an impact on customer satisfaction measured by the number of customers (household, industries etc) and number of towns/villages, that are served by each company.

\section{--TABLE 2 HERE--}

Applying input/output data to model (3), the following formulation is derived (8). In formulation (8), regarding the inputs, NSTAFF stands for the number of staff; NCONSM stands for net consumption, NTRANF stands for the number of transformers; LENGTHCABLES stands for the length of cables and INCAP for installed capacity. Intermediate output is only energy supply, denoted with ENSUPPLY. The undesirable outputs that are considered are ANFAULTS (annual faults and interruptions) and ENLOSSES (energy losses). Final outputs that model number of customers and towns/villages served by each company are denoted as NUMCUST and NUMToVill correspondingly. 
$\max \beta$

s.t.

$$
\begin{aligned}
& \sum_{j=1}^{n} \hat{\lambda}_{j}^{1} \cdot \operatorname{NSTAFF}_{j} \leq \theta^{s 1} \cdot \operatorname{NSTAFF}_{j_{0}} \\
& \sum_{j=1}^{n} \hat{\lambda}_{j}^{1} \cdot \operatorname{NCONSM}_{j} \leq \theta^{s 1} \cdot \operatorname{NCONSM}_{j_{0}} \\
& \sum_{j=1}^{n} \hat{\lambda}_{j}^{1} \cdot \operatorname{NTRANSF}_{j} \leq \theta^{s 1} \cdot \operatorname{NTRANSF}_{j_{0}} \\
& \sum_{j=1}^{n} \hat{\lambda}_{j}^{1} \cdot \text { LENGTHCABLES }_{j} \leq \theta^{s 1} \cdot \text { LENGTHCABLES }_{j_{0}}
\end{aligned}
$$$$
\sum_{j=1}^{n} \hat{\lambda}_{j}^{1} \cdot I N C A P_{j} \leq \theta^{s 1} \cdot I N C A P_{j_{0}}
$$$$
\sum_{j=1}^{n} \hat{\lambda}_{j}^{1} \cdot \operatorname{ENSUPPLY}_{j} \geq \sum_{j=1}^{n} \lambda_{j}^{2} \cdot \operatorname{ENSUPPLY}_{j}
$$$$
\sum_{j=1}^{n} \hat{\lambda}_{j}^{1} \cdot \operatorname{ANFAULTS}_{j} \leq(1-\beta) \cdot \operatorname{ANFAULTS}_{j_{0}}
$$$$
\sum_{j=1}^{n} \hat{\lambda}_{j}^{1} \cdot \operatorname{ENLOSSES}_{j} \leq(1-\beta) \cdot \text { ENLOSSES }_{j_{0}}
$$

Profit Efficiency extraction is based on the same data (inputs and outputs) using formulation (7). Expanded model (9) is described below. The objective function entails prices for energy 
supply (TL/MWh) denoted with $p^{1}$, average unit price per customer, as in this category there may be either households or industries that may be served by each company denoted with $p^{2}$ expressing (TL) and average price per town or village served denoted with $p^{3}$ expressed in (TL). Cost function consists of the costs that is associated with energy losses, expressed in lost sales denoted with $c^{1}$ (TL/MWh), the cost that is associated with a fixed value for each case that a fault may occur $c^{2}$ (TL) and labor cost (labc) expressed with (TL). 
$\max \Pi=\sum_{j=1}^{n}\left[\begin{array}{l}p^{1} \cdot \text { ENSUPPLY }_{j}+p^{2} \cdot \text { NCUST }_{j}+p^{3} \cdot \text { NUMToVill }_{j}- \\ \left(c^{1} \cdot \text { ENLOSSES }_{j}+c^{2} \cdot \text { ANFAULTS }_{j}+\text { labc } \cdot \text { NSTAFF }_{j}\right. \\ \left.m \cos t^{1} \cdot \text { NSTAFF }_{j}\right)\end{array}\right]$

s.t.

$$
\begin{aligned}
& \sum_{j=1}^{n} \lambda_{j}^{1} \cdot \operatorname{NSTAFF}_{j} \leq \operatorname{NSTAFF}_{j_{0}} \\
& \sum_{j=1}^{n} \lambda_{j}^{1} \cdot \operatorname{NCONSM}_{j} \leq \operatorname{NCONSM}_{j_{0}} \\
& \sum_{j=1}^{n} \lambda_{j}^{1} \cdot \operatorname{NTRANSF}_{j} \leq \operatorname{NTRANSF}_{j_{0}}
\end{aligned}
$$$$
\sum_{j=1}^{n} \lambda_{j}^{1} \cdot \text { LENGTHCABLES }_{j} \leq \text { LENGTHCABLES }_{j_{0}}
$$$$
\sum_{j=1}^{n} \lambda_{j}^{1} \cdot I N C A P_{j} \leq I N C A P_{j_{0}}
$$$$
\sum_{j=1}^{n} \lambda_{j}^{1} \cdot \operatorname{ENSUPPLY}_{j} \geq \sum_{j=1}^{n} \lambda_{j}^{2} \cdot \operatorname{ENSUPPLY}_{j}
$$

$$
\sum_{j=1}^{n} \lambda_{j}^{1} \cdot \text { ANFAULTS }_{j}=\text { ANFAULTS }_{j_{0}}
$$$$
\sum_{j=1}^{n} \lambda_{j}^{1} \cdot \text { ENLOSSES }_{j}=\text { ENLOSSES }_{j_{0}}
$$$$
\sum_{j=1}^{n} \lambda_{j}^{2} \cdot N U M C U S T_{j} \geq N U M C U S T_{j_{0}}
$$$$
\sum_{j=1}^{n} \lambda_{j}^{2} \cdot \text { NUMToVill }_{j} \geq N U M T o \text { Vill }_{j_{0}}
$$$$
\sum_{j=1}^{n} \lambda_{j}^{1}=1
$$$$
\sum_{j=1}^{n} \lambda_{j}^{2}=1
$$

$\lambda_{j}^{1} \geq 0, j=1, \ldots, n$

$\lambda_{j}^{2} \geq 0, j=1, \ldots, n$

Assuming that the projected value of a DMU, would suggest an extreme increase in energy supply (ENSUPPLY), then this increase could be achieved by expansion of capacity and additional cost in assets, capital, labor force etc. For example, if energy supply increases over a threshold ( ENSUPPLY ${ }_{j}^{\text {threshold }}$ ), then an additional cost would have to be added to the overall 
cost of that specific company. Based on constraint (10), if left hand side that models the optimal value of DMU $j$ is more than ENSUPPLY $Y_{j}^{\text {threshold }}$ then binary variable $\Lambda$ yields a value of 1 , otherwise it provides a value of 0 .

$\sum_{j=1}^{n} \lambda_{j}^{1} \cdot \operatorname{ENSUPPLY}_{j} \geq \operatorname{ENSUPPLY}_{j_{0}}^{\text {threshold }} \cdot \Lambda$

This constraint is linked with objective function with the following additional term in objective function $\operatorname{Exp} C o s t \cdot \Lambda$; ExpCost expresses the expansion costs that company $j$ must invest, in order to provide the additional energy supply. The final DEA formulation is (11). The threshold that has been used in this instance is equal to the mean value of ENSUPPLY ${ }_{j}$. 
s.t.

$$
\begin{aligned}
& \sum_{j=1}^{n} \lambda_{j}^{1} \cdot N S T A F F_{j} \leq N S T A F F_{j_{0}} \\
& \sum_{j=1}^{n} \lambda_{j}^{1} \cdot \operatorname{NCONSM}_{j} \leq \operatorname{NCONSM}_{j_{0}} \\
& \sum_{j=1}^{n} \lambda_{j}^{1} \cdot N T R A N S F_{j} \leq N T R A N S F_{j_{0}} \\
& \sum_{j=1}^{n} \lambda_{j}^{1} \cdot \text { LENGTHCABLES }_{j} \leq \text { LENGTHCABLES }_{j_{0}} \\
& \sum_{j=1}^{n} \lambda_{j}^{1} \cdot I N C A P_{j} \leq I N C A P_{j_{0}} \\
& \sum_{j=1}^{n} \lambda_{j}^{1} \cdot \operatorname{ENSUPPLY}_{j} \geq \sum_{j=1}^{n} \lambda_{j}^{2} \cdot \operatorname{ENSUPPLY}_{j} \\
& \sum_{j=1}^{n} \lambda_{j}^{1} \cdot \text { ANFAULTS }_{j}=\text { ANFAULTS }_{j_{0}} \\
& \sum_{j=1}^{n} \lambda_{j}^{1} \cdot \text { ENLOSSES }_{j}=\text { ENLOSSES }_{j_{0}} \\
& \sum_{j=1}^{n} \lambda_{j}^{2} \cdot N U M C U S T_{j} \geq N U M C U S T_{j_{0}} \\
& \sum_{j=1}^{n} \lambda_{j}^{2} \cdot \text { NUMToVill }_{j} \geq \text { NUMToVill }_{j_{0}} \\
& \sum_{j=1}^{n} \lambda_{j}^{1} \cdot \operatorname{ENSUPPLY}_{j} \geq \operatorname{ENSUPPLY}_{j_{0}}^{\text {threshold }} \cdot \Lambda \\
& \sum_{j=1}^{n} \lambda_{j}^{1}=1 \\
& \sum_{j=1}^{n} \lambda_{j}^{2}=1 \\
& \lambda_{j}^{1} \geq 0, j=1, \ldots, n \\
& \lambda_{j}^{2} \geq 0, j=1, \ldots, n \\
& \Lambda \in\{0,1\}
\end{aligned}
$$




\section{Results}

\subsection{Efficiency based on radial measure}

In this section, the radial efficiency is extracted based on DEA model (8). The DEA model presented has been modeled and solved with GAMS, using CPLEX as LP solver. As it can be seen from Table 3, the companies that underperform are E8, E9, E10, E11, E12, E13, E14, E16, E17, E18, E19 and E20. The company with the largest percentage of inefficiency is E19 with $\beta=0.3397$ whereas the company with the lowest is E9 with $\beta=0.0334$.

\section{--TABLE 3 HERE--}

Due to limited data, one distribution company was excluded from the analysis. The remaining 20 companies constitute approximately $90 \%$ of market share in the sector. Efficient companies according to model (8) are E1, E2, E3, E4, E5, E6, E7 and E15. Efficiency based on radial measure consider as efficient the companies which are located especially in southeast region of Turkey. These companies are E1, E2, E3, E4, E5 and E6. And these companies demonstrate very frequency of annual faults and interrupts per customers as seen in Fig. 3.

\section{--FIGURE 3 HERE--}

As seen from Figure 3, the companies which have the high number of annual faults and interrupts per customers values are considered as efficient companies according to efficiency based radial measure model (8). It is known that unregistered subscribers are also fairly common in south-east region are of Turkey. By considering all these cases, these findings reduce the reliability of the efficiency results of radial measure model (8). 
To consider the reference sets results for inefficient companies, radial measures of model (8), optimal lambda (peers) values, are considered. The optimal lambda (peers) values $\left(\hat{\lambda}_{j}^{1,{ }^{*}}, \lambda_{j}^{2, *}\right)$ that are derived from model (8) are presented in the following tables (Tables 4-5) for each company (DMU).

--TABLE 4 HERE--

--TABLE 5 HERE--

\subsection{Efficiency based on profit efficiency}

In this section, the results of profit efficiency are reported. The resulting network DEA model (11) is formulated as Mixed Integer Linear Programming (MILP) model and has been solved using GAMS, using CPLEX as MILP solver. In Table 6, the Profit Efficiency (PE) is shown, whereas, $P E=\frac{\Pi^{*}}{\max \left\{\Pi^{*}\right\}}$. As it can be seen in Table 6, the largest value for profit efficiency is reported for company 16. The lowest value has been reported for company E2 which is one of the efficient companies according to results of model (8). Based on model (11), additional capital for expansion in their infrastructure and for investments has been reported for companies E1, E7, E10, E11, E16.

\section{--TABLE 6 HERE--}

According to results in Table 6, E16 is only efficient company. Profit efficiency model decreased the number of efficient DMUs, thus it increased discrimination power. By taking into account profit and expansion cost idea in the objective function, it reflects more realistic result by making E16 efficient, which has very potential customers as house holders and 
industry, E16 has the highest electric suppy and amout of customers value in Turkey as seen in Figure 4 and Figure 5 .

\section{--FIGURE 4 HERE--}

\section{--FIGURE 5 HERE--}

Company, E16 is the biggest electric distribution company in Turkey producing 19.184.186 MWh energy supply and 4.202.132 customers (as both householder and industry). The optimal lambda (peers) values $\left(\lambda_{j}^{1, *}, \lambda_{j}^{2, *}\right)$ that are derived from model (11) are presented in the Tables 7 and 8 for each company (DMU). By considering both Tables 4- 5 and Tables 78, the optimal lambda (peers) values results which are indicators for reference sets of both radial efficiency model and profit efficiency model are consistent with each other.

\section{--TABLE 7 HERE--}

\section{--TABLE 8 HERE--}

A comparison of the empirical cumulative density functions (ECDF) of the two types of efficiency (1- $\beta$ and $P E$ ) calculated based on models (8) and (11) respectively, is shown in Figure 6. With the use of ECDF plots, several conclusions can be drawn regarding the distribution of efficiency. The efficiency derived from model (8), does not have a high discrimination power as almost $60 \%$ of the DMUs have efficiency of 1 . This fact hinders the ranking of the units. On the contrary, based on the efficiency of model (11), only a single DMU has efficiency equal to 1 providing a clearer measure for ranking.

\section{--FIGURE 6 HERE--}


Besides examining the profit efficiency, other indices, can provide valuable information. Based on Figure 7, even if the largest value of profit is reported for company E16, in Profit/Customer index company E16 is ranked low. This profitability ratio can be balanced if there are imports of energy from one company to another, in case of energy deficiency caused by high demand. On the contrary, in the profitability index Profit/Asset, company E16 which has the highest profit, is ranked in a higher position while the highest position is reported for company E13. An information that is provided from this type of analysis is that E13 makes more efficient use of its assets, compared to any other company due to higher values of profit generated by more efficient use of its assets.

\section{--FIGURE 7 HERE--}

The proposed model measures, through a novel Network DEA model, the profit efficiency of distribution companies in Turkey. However, in order to further evaluate the qualitative and quantitative characteristics of the profit efficiency score for each distribution company, several comparisons should be made. Financial ratios, such as profit per customer, utilize information based on revenues and expenses providing conclusions based on purely economic and financial data. However, the profit efficiency as derived from the proposed model, defines profit as a function of multiple attributes and external factors that affect the underlying assumed production function. For sake of comparison and ranking construction of the distribution companies based on financial ratios and profit efficiency, several financial ratios are calculated.

More specifically, two indices are constructed, namely profitability ratio which is defined as the fraction of profits per customer and profitability index which is defined as the fraction of profits per asset. Both indices are compared with profit efficiency score as derived from the proposed Network DEA model. As shown in Figure 8 (a), the company with the largest profit 
efficiency is E16. However, distribution company E19 has higher values in the profit per customer ratio. Based on this index, E19 is more profitable compared to distribution company E16, even if both companies serve approximately equal number of customers (E16: 1,362,922, E19: 1,555,424). Nevertheless, in terms of the proposed Network DEA analysis, profit efficiency of distribution company E19 is quite low, leading to the conclusion that the profitability index may not lead to efficient operation and capital management. Besides the electric distribution companies that act as outliers in Figure 8 a), electric distribution companies E2, E12, have high values of profit per customer with low values of profit efficiency. Low values in profit efficiency lead to the conclusion that the aforementioned companies do not utilize efficiently their resources and there are opportunities to achieve higher profits. On the contrary, higher profit efficiency and medium profit per customer values are reported for distribution company E13. A straightforward conclusion is that this company makes better use of the available resources, as even if it serves 849.714 customers, which is significantly low compared to other distribution companies, the corresponding profit efficiency is quite high.

\section{--FIGURE 8 HERE--}

High profit values per customer index for distribution companies E1 and E14 are reported however, their corresponding profit efficiency values are medium. The same conclusion can be drawn regarding resource utilization with distribution company E13.

Regarding the profit per asset index electric distribution companies are compared with profit efficiency as derived from the proposed Network DEA model. From Figure $9 b$ ), it can be seen that electric distribution company E16 has the highest profit efficiency and the second largest value in profit per asset index. The highest value in profit per asset index i electric distribution company E13; the corresponding profit efficiency in percentage is $48.19 \%$ which 
is a medium value. The number of assets (number of transformers) of electric distribution company E13, is significantly low while the profit efficiency is quite high compared to other distribution companies. However, based on the fact that the profit efficiency is $48.19 \%$, this company does not make full use of its resources and can be improved with optimized resource utilization. The electric distribution company with the third higher profit per asset index is E10. This electric distribution company has a high profit efficiency score (74.34\%).

However, the comparison cannot provide special characteristics regarding the distribution of values of the financial indices (profit per customer and profit per asset) and the profit efficiency score. The 2-dimensional density estimation of profit per customer and profit efficiency is shown in Figure 9. More specifically, the points show the pairs of profit/customer and profit efficiency for each electric distribution company while the contours (isoquant lines) show the intensity of the distribution. It can be seen that the majority of the points are concentrated in the interval of less than $200 \mathrm{M}$ TL for profit efficiency (x-axis) and less than $100 \mathrm{TL}$ for profit per customer index. This is an interesting finding as demonstrates that the majority of electric distribution companies demonstrate low values of profit efficiency and profit per customer using properly in most of the cases their resources.

\section{--FIGURE 9 HERE--}

The 2-dimensional density estimation of profit per asset and profit efficiency is shown in Figure 10. It can be seen that the majority of the points are concentrated in the interval of less than $100 \mathrm{M}$ TL for profit efficiency (x-axis) and less than $1000 \mathrm{TL}$ for profit per asset index. 


\section{Discussion}

In this paper, a new model based on profit efficiency has been applied to electric sector in Turkey. Electric distribution companies is an electrical power supplier for electrical transmission. From this aspect, they can be considered as a very crutial part of the electricity process and the profit can be a tool for them. Hence, electric distribution companies are the effective ones for whole electricity sector and taking them into account of profitability of the sector is a new aspect and original part of the research. Because of being a developing country and activity of privatizing policy in the sector, selecting of Turkey's electric distribution companies is also crutial point of the study. Additionally, the theory which is developed in this study could be applicable in any other industries and varied geographical locations.

Profit based objective function approach is a new idea in efficiency measurement process of electric distribution companies. The results are reliable and make sense for the problem at hand. Especially, the proposed model considered only one company as an efficient to clarify the best company in the sector and from this aspect, yielding a valuable discussion ability for researchers. In addition, when the scores of proposed model are ranked, it can be found that the some of the electric distribution companies have better performance than the others. These orders of efficiency are the result of a profit and cost-based approach underlying the model. The costs and profit values are specific currency values for Turkish electric distribution sector, and this point is the limitation of the model. The model can also be adapted to electric distribution sector of other countries by changing the coefficients in objective function and constraints. This issue can be considered as a scope of future researches and the model can be adapted to other countries. 
Measuring the performance of electric distribution companies provides valuable insight for a country level. An a-priori knowledge of performance of a company is important as the capacity of each company can be optimized due to exact knowledge of the resources. Based on the proposed network DEA model, the state can assess the performance of each electric distribution company and subsequently perform a series of actions regarding the improvement of their efficiency. A measure that can help towards this direction is to set a strict framework for reducing energy losses. Better quality management of the assets and capital of each company can potentially lead to less disruptions in the operations of each company, and eventually, to more profit.

According to profit efficiency approach, the companies which are located in the south part of Turkey concentrate high inefficiency and their efficiency scores are significantly lower than the companies in the west part of Turkey. Especially, the companies which are responsible from Kizılırmak part of Anatolian region, eastern Anatolian region and south-eastern Anatolian region have very low efficiency scores in terms of profit efficiency. In eastern and central Black Sea region, the companies have also low profit efficiency values. Furthermore, it is noteworthy that there is a significant difference between efficiency scores of two distribution companies in Thrace (Trakya) region. The companies in Aegean region and Mediterranean region demonstrate better performance than other regions. According to the results, it can be suggested that, the precautions should be taken to reduce the amount of energy losses and illegal uses and increase the number of subscribers and customers in Kizilırmak part of Anatolian region, eastern Anatolian region and south-eastern Anatolian region. This can be achieved with competitive prices of high quality services. The companies that serve the coastal areas tend to capture this high quality. 


\section{Conclusions}

Benchmarking of the electric distribution companies in the sector has become a subject that is studied widely nowadays due to the effect of privatization policies for developing countries. Several studies have been proposed for efficiency evaluation of electric distribution companies in various countries around the world. The common feature of these studies is performance measurement using the relative efficiency of companies using DEA, SFA, Malmquist Index by considering the variables related with the electricity distribution. In this paper Network DEA methodology has been employed which reflects realistically the measurement of productivity of systems or sectors that have intermediate products which are outputs from one process and are used as inputs for another procedds. In this paper a new profit efficiency network DEA model by using a new objective function and threshold value in constraint as a modification of Directional Distance Function (DDF) network DEA approach is proposed. The proposed model provides the ability to take incorporate undesirable outputs and reflects prices and profits in electricity sector. Undesirable output and prices-profit models take into consideration the efficiency measurement process of electric distribution companies. The proposed model aims to measure the efficiency of Turkish electric distribution companies by proposing a new model by taking into account profit efficiency and expansion cost at the same time in Network DEA. From this aspect, the proposed model help to develop a policy for practitioners by considering more realible results. The models that have been used in this paper utilise radial efficiency and profit effiency. The latter model (profit efficiency) has been modified in order to take into account external effects to DMUs. More specifically, for each DMU examined, a new set of constraint has been introduced in order to analyse whether the specific DMU exceeds a predefined threshold; if so, a cost is associated with the DMU (electric distribution company), on the basis of an expansion cost. Regarding radial efficiency measure model 8 electric 


\section{References}

1. Abbott, M. (2006). The productivity and efficiency of the Australian electricity supply industry, Energy Economics, 28, 444-454.

2. Annual Report of Ministry of Energy and Natural Resources, Ankara, Turkey; 2011. http://www.tedas.gov.tr/sx.web.docs/tedas/docs/faaliyetrapor//Tr_Web_Versiyon_Ted as_2011_Faaliyet_raporu.pdf

3. Arcos-Vargas, A., Núñez-Hernández, F., \& Villa-Caro, G. (2017). A DEA analysis of electricity distribution in Spain: An industrial policy recommendation. Energy Policy, $102,583-592$.

4. Bagdadioglu, N., Price, C. M. W., \& Weyman-Jones, T. G. (1996). Efficiency and ownership in electricity distribution: a non-parametric model of the Turkish experience. Energy Economics, 18(1-2), 1-23.

5. Bagdadioglu, N., Basaran, A., Price, C.M.W. (2007). Potential impact of electricity reforms on Turkish households. University of East Anglia ESRC Centre for Competition Policy and Norwich Business School, CCP Working Paper No. 07-8.

6. Charnes, A., Cooper, W. W., \& Rhodes, E. (1978). Measuring the efficiency of decision making units. European journal of operational research, 2(6), 429-444.

7. Chung, Y. H., Färe, R., \& Grosskopf, S. (1997). Productivity and undesirable outputs: a directional distance function approach.journal of Environmental Management, 51(3), 229-240. Competition Policy and Norwich Business School, CCP Working Paper No. 07-8.

8. Colak, I., Bayindir, R., Fulli, G.,Tekin, I., Demirtas, K., Covrig, C., (2014) Smart grid opportunities and applications in Turkey, Renewable and Sustainable Energy Reviews $33: 344-352$. 
9. Cullman, A., Hirschhausen, C. (2006). Efficiency analysis of East European electricity distribution in transition: legacy of the past? Journal of Productivity Analysis, 29:155-167.

10. Cullman, A., Crespo, H., Plagnet, M.A. (2008). International Benchmarking in Electricity Distribution: A Comparison of French and German Utilities. German Institute for Economic Research Discussion Paper, 830: 1-27.

11. Deng, N. Q., Liu, L. Q., \& Deng, Y. Z. (2017). Estimating the effects of restructuring on the technical and service-quality efficiency of electricity companies in China. Utilities Policy.

12. Edvardsen, D.F., Forsund, F.R. (2003). International benchmarking of electricity distribution utilities. Resource and Energy Economics, 25, 353-371.

13. Filippini, M., \& Wetzel, H. (2014). The impact of ownership unbundling on cost efficiency: Empirical evidence from the New Zealand electricity distribution sector. Energy economics, 45, 412-418.

14. Forsund, F.R., Kittelsen, S.A.C. (1998). Productivity development of Norwegian electricity distribution utilities. Resource and Energy Economics, 20, 207-224.

15. Giannakis, D., Jamasb, T., Pollitt, M. (2005). Benchmarking and incentive regulation of quality of service: An application to the UK electricity distribution networks. Energy Policy, 33, 2256-2271.

16. Ghasemi, M., \& Dashti, R. (2017). A risk-based model for performance-based regulation of electricity distribution companies. Utilities Policy, 45, 36-44.

17. Goto, M., Tsutsui, M. (1998). Comparison of Productive and Cost Effciencies Among Japanese and US Electric Utilities", International Journal of Management Science, 26 (2),177-194. 
18. Gouveia, M. C., Dias, L. C., Antunes, C. H., Boucinha, J., \& Inácio, C. F. (2015). Benchmarking of maintenance and outage repair in an electricity distribution company using the value-based DEA method. Omega, 53, 104-114.

19. Hess, B., Cullman A. (2007). Efficiency analysis of East and West German electricity distribution companies - Do the "Ossis" really beat the "Wessis"? Utilities Policy, $15,206-214$.

20. Jamasb, T., Pollitt, M. (2003). International benchmarking and regulation: An application to European electricity distribution utilities. Energy Policy, 31, 16091622.

21. Korhonen, P.J., Syrjanen, M.J. (2003). Evaluation of cost efficiency in Finnish electricity distribution. Annals of Operations Research, 121, 105-122.

22. Lozano, S., Gutiérrez, E., \& Moreno, P. (2013). Network DEA approach to airports performance assessment considering undesirable outputs. Applied Mathematical Modelling, 37(4), 1665-1676.

23. Mirza, F. M., Mushtaq, I., \& Ullah, K. (2017). Assessing the efficiency dynamics of post reforms electricity distribution utilities in Pakistan. Utilities Policy, 47, 18-28.

24. Omrani, H., Beiragh, R. G., \& Kaleibari, S. S. (2015). Performance assessment of Iranian electricity distribution companies by an integrated cooperative game data envelopment analysis principal component analysis approach. International Journal of Electrical Power \& Energy Systems, 64, 617-625.

25. Official Newspaper of Republic of Turkey, No: 25422, Ankara, Turkey; 2004. http://www.resmigazete.gov.tr/eskiler/2004/04/20040403.html

26. Örkcü, H.H., Unsal, M.G., Bal, H., “A modification of a mixed integer linearprogramming (MILP) model to avoid the computational complexity", Annals of Operations Research, 235 (1), 599-623, 2015. 
27. Pahwa, A., Feng, X., Lubkeman, D. (2002). Performance evaluation of electricity distribution utilities based on data envelopment analysis. IEEE Transactions on Power Systems, 17, 400-405.

28. Pombo, C., Taborda, R. (2006). Performance and efficiency in Colombia's power distribution system: Effects of the 1994 reform. Energy Economics, 28, 339-369.

29. Retzlaff-Roberts, D. L. (1996). Relating discriminant analysis and data envelopment analysis to one another. Computers \& operations research, 23(4), 311-322.

30. Souza, M.V., Diallo, M., Souza, R.C., Baidya, T.K. (2010). The Cost Efficiency of the Brazilian Electricity Distribution Utilities: A Comparison of Bayesian SFA and DEA Models. Hindawi Publishing Corporation Mathematical Problems in Engineering Volume, Article ID 593059, 20 pages.

31. Sartori, S., Witjes, S., \& Campos, L. M. (2017). Sustainability performance for Brazilian electricity power industry: An assessment integrating social, economic and environmental issues. Energy Policy, 111, 41-51.

32. Sueyoshi, T., \& Goto, M. (2011). DEA approach for unified efficiency measurement: assessment of Japanese fossil fuel power generation. Energy Economics, 33(2), 292303.

33. Sueyoshi, T., \& Goto, M. (2016). Undesirable congestion under natural disposability and desirable congestion under managerial disposability in US electric power industry measured by DEA environmental assessment. Energy Economics, 55, 173-188.

34. Turkish Electricity Transmission Company (TETC). Turkey Electricity Statistic 2011, Ankara, Turkey; 2012.

http://www.teias.gov.tr/TürkiyeElektrikİstatistikleri/istatistik2010/İstatistik\%202010. $\underline{\text { html. }}$

35. Welch, E., \& Barnum, D. (2009). Joint environmental and cost efficiency analysis of electricity generation. Ecological Economics, 68(8-9), 2336-2343. 
36. Xie, B. C., Gao, J., Chen, Y. F., \& Deng, N. Q. (2018). Measuring the efficiency of grid companies in China: A bootstrapping non-parametric meta-frontier approach. Journal of Cleaner Production, 174, 1381-1391.

37. Yadav, V. K., Padhy, N. P., \& Gupta, H. O. (2011). Performance evaluation and improvement directions for an Indian electric utility. Energy policy, 39(11), 71127120.

38. Yunos, J.M., Hawdon, D. (1997). The efficiency of the National Electricity Board in Malaysia: An intercountry comparison using DEA. Energy Economics, 19, 255-269.

39. Zhang, Y., Bartels, B. (1998). The effect of sample size on the mean efficiency in DEA with an application to electricity distribution in Australia, Sweden and New Zealand. Journal of Productivity Analysis, 9, 187-204.

40. Zorzo, L. S., Diehl, C. A., Venturini, J. C., \& Zambon, E. P. (2017). The relationship between the focus on innovation and economic efficiency: a study on Brazilian electric power distribution companies. RAI Revista de Administração $e$ Inovação, 14(3), 235-249. 


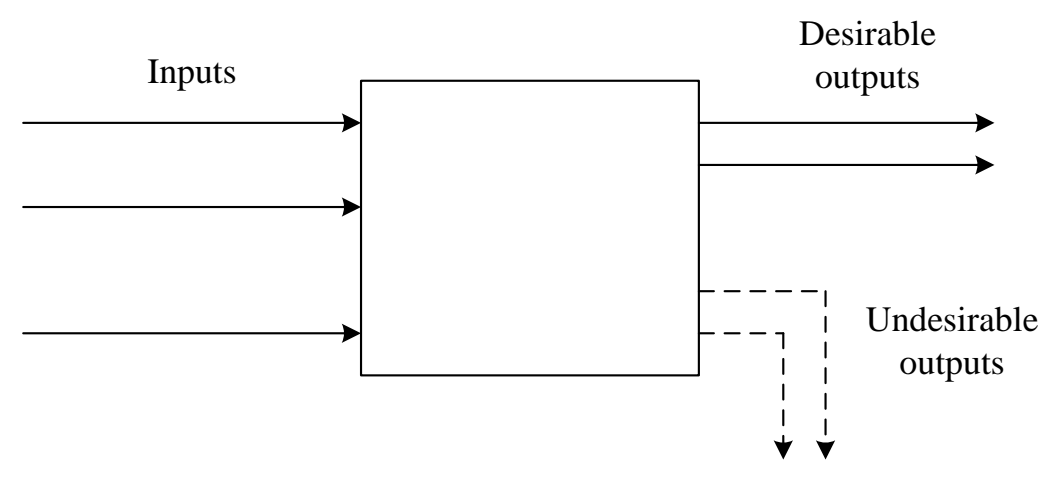

Figure 1: A production process with desirable and undesirable outputs. 


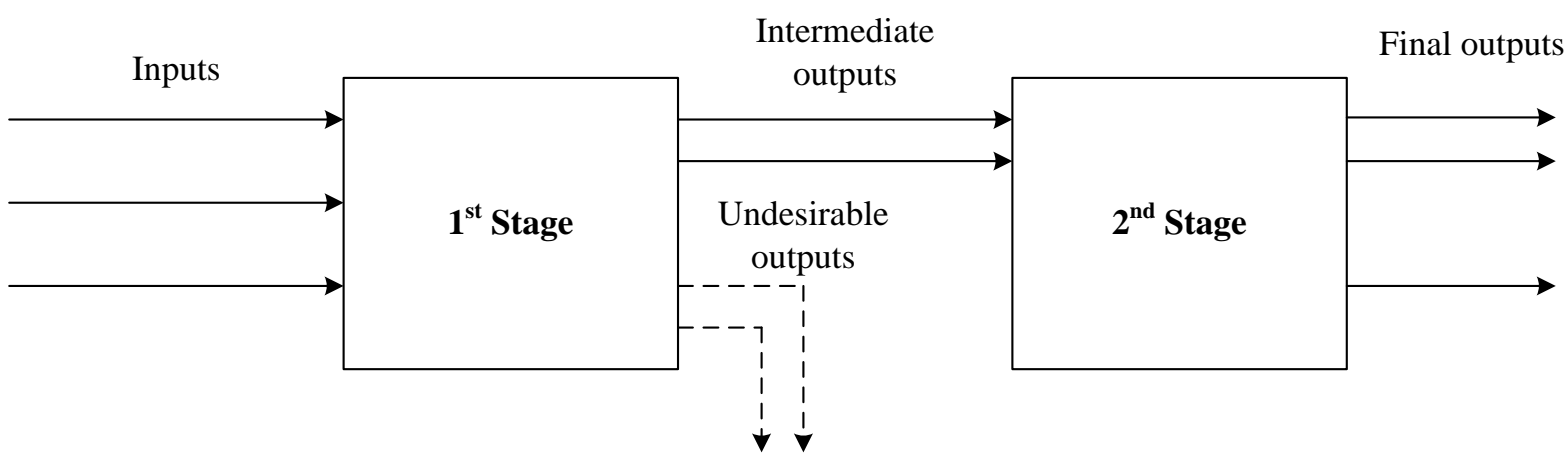

Figure 2: A two-stage production process. 


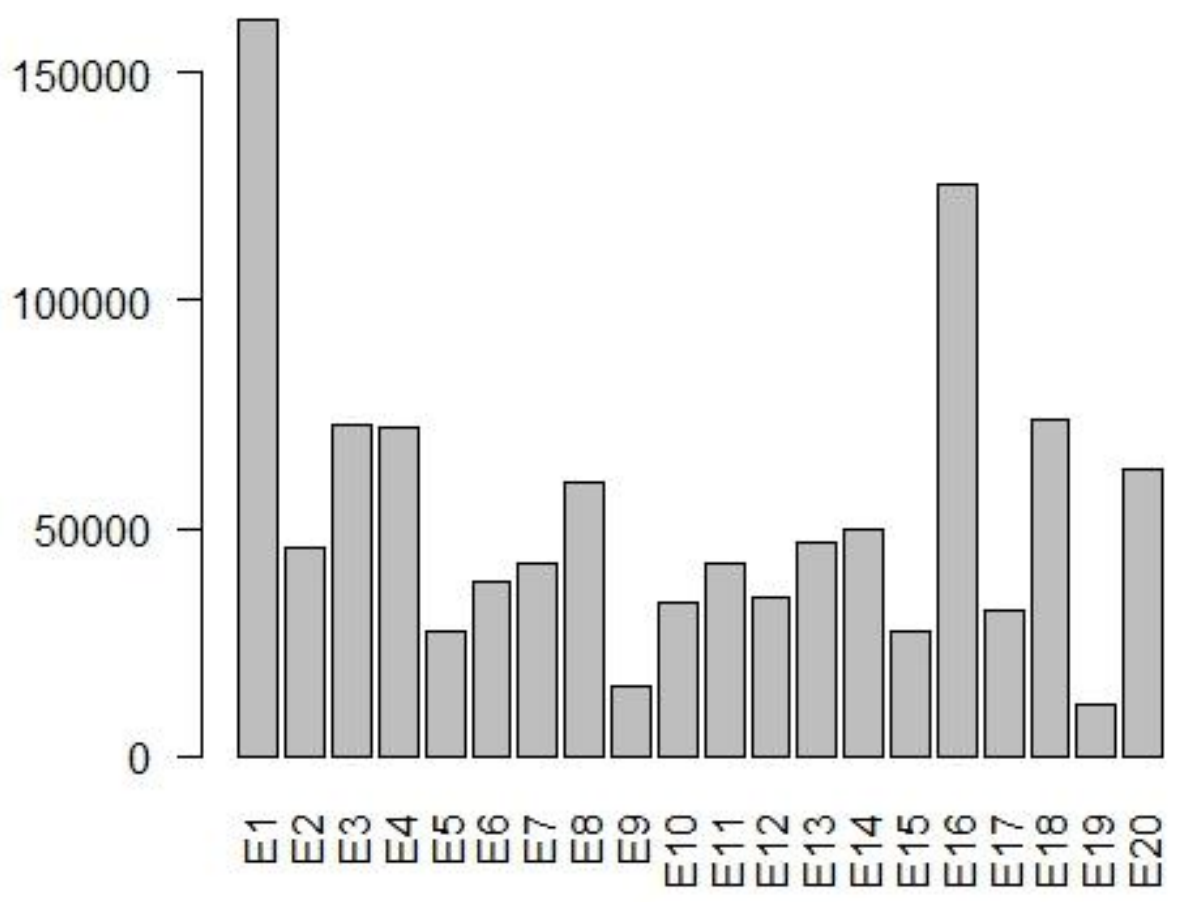

Figure 3: Annual faults and interrupts per customers values for electricity distribution companies 


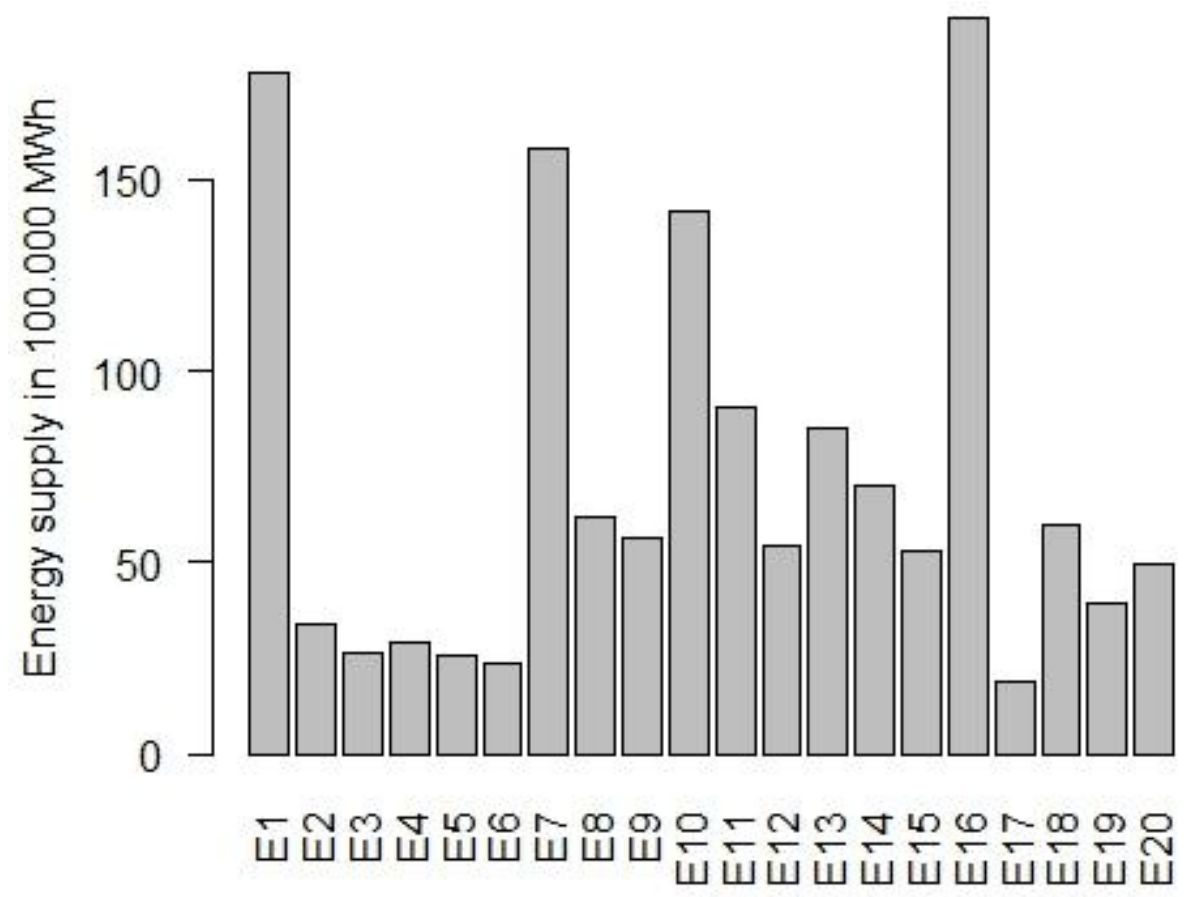

Figure 4: Energy supply values for electricity distribution companies 


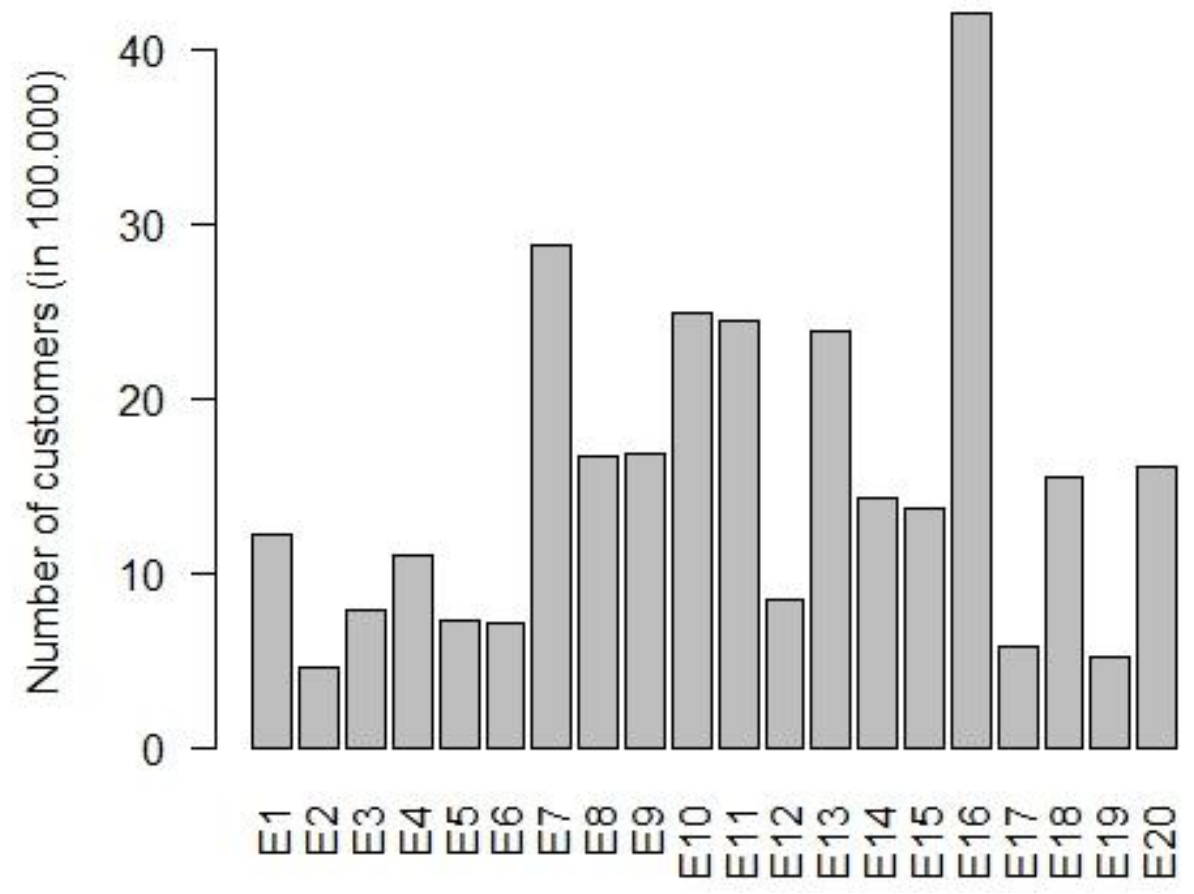

Figure 5: Number of Customers values for electricity distribution companies 

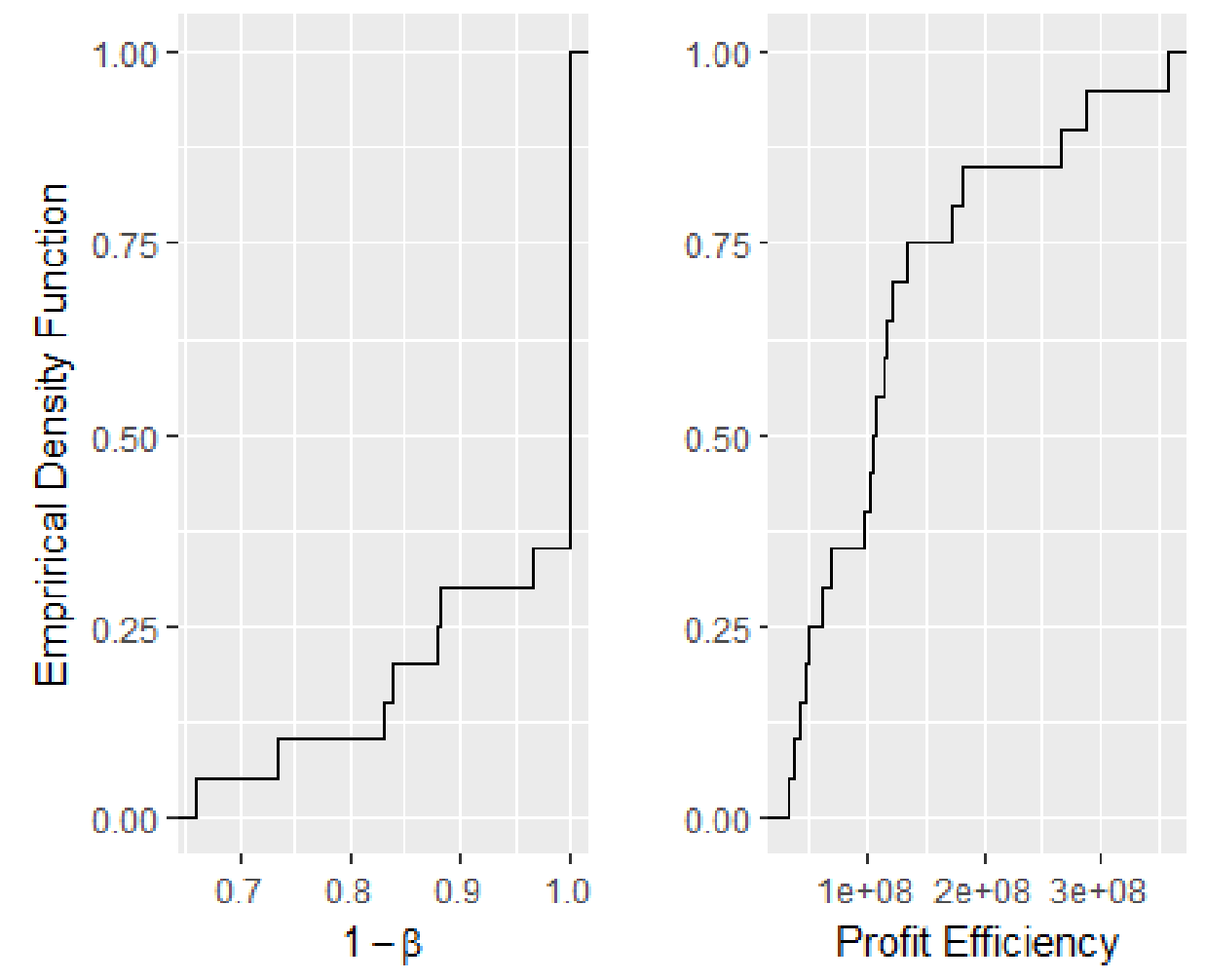

Figure 6: Joint ECDF plot of 1- $\beta$ (model 8$)$ and Profit Efficiency (model 11). 

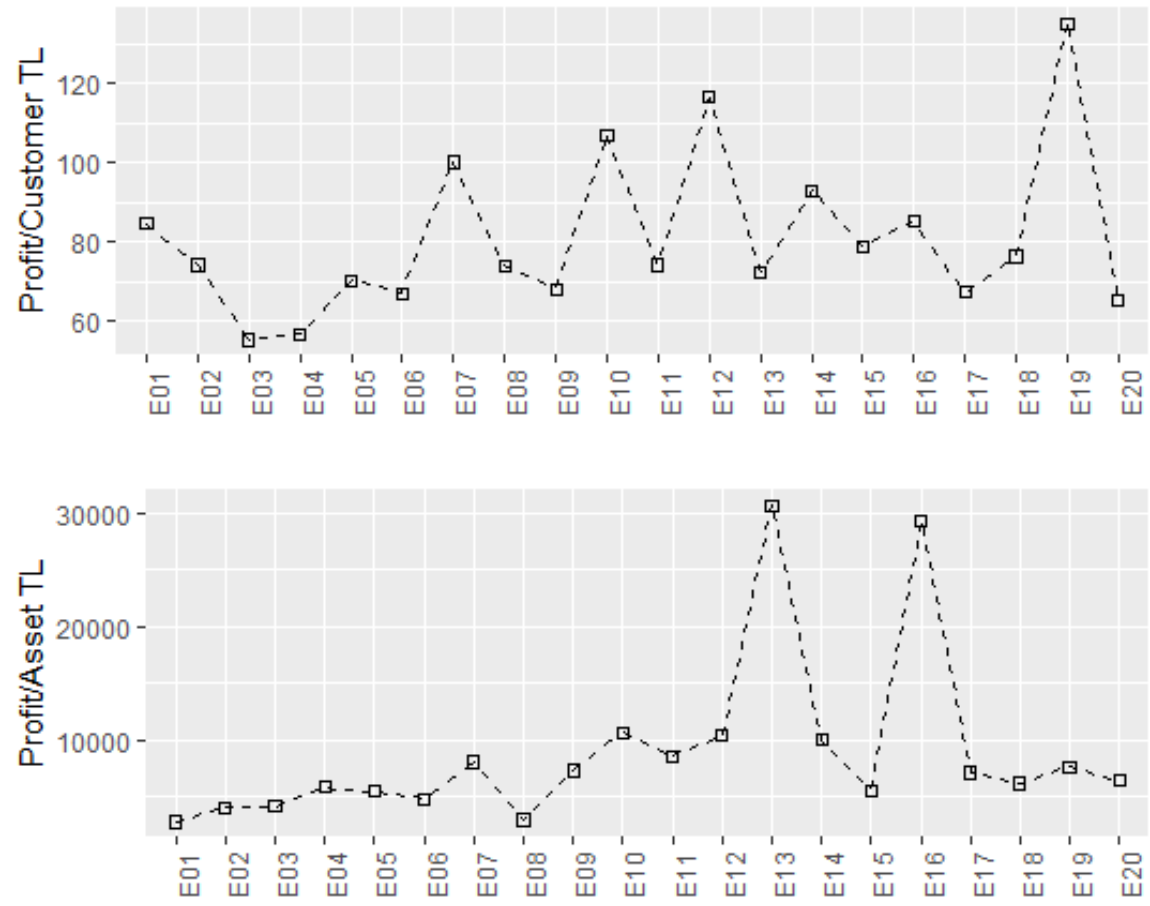

Figure 7: Line plots of Profit/Customer and Profit/Asset indicators. 


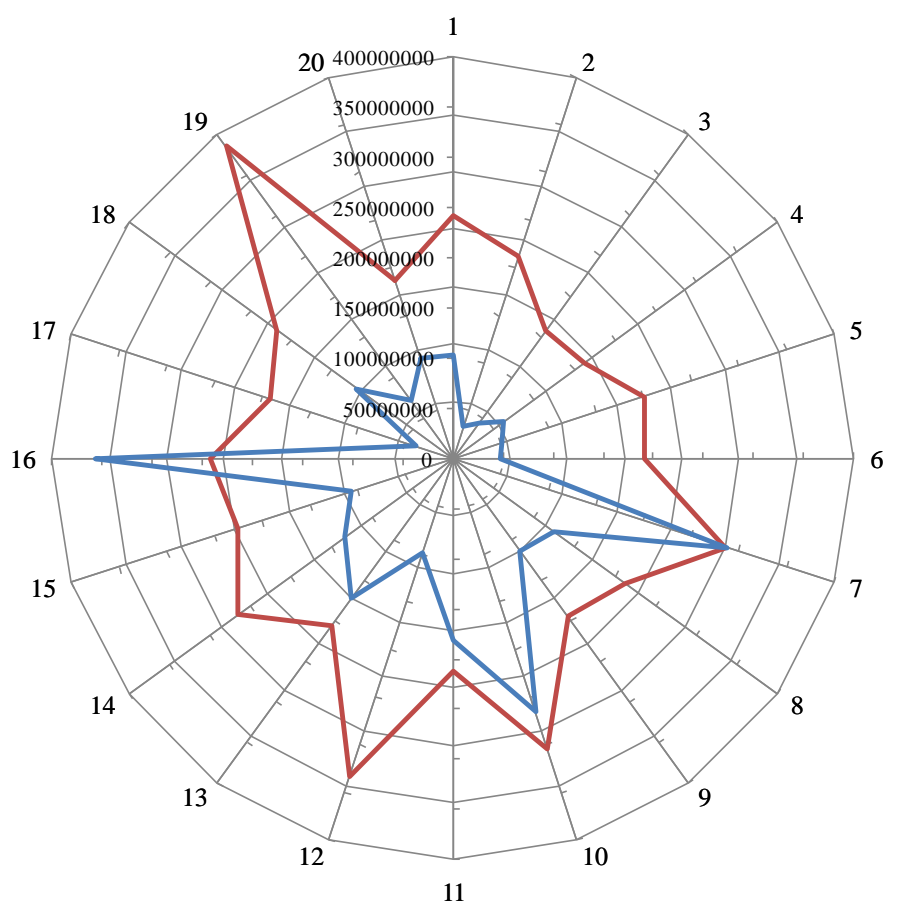

—Profit/Customer — Profit efficiency

(a)

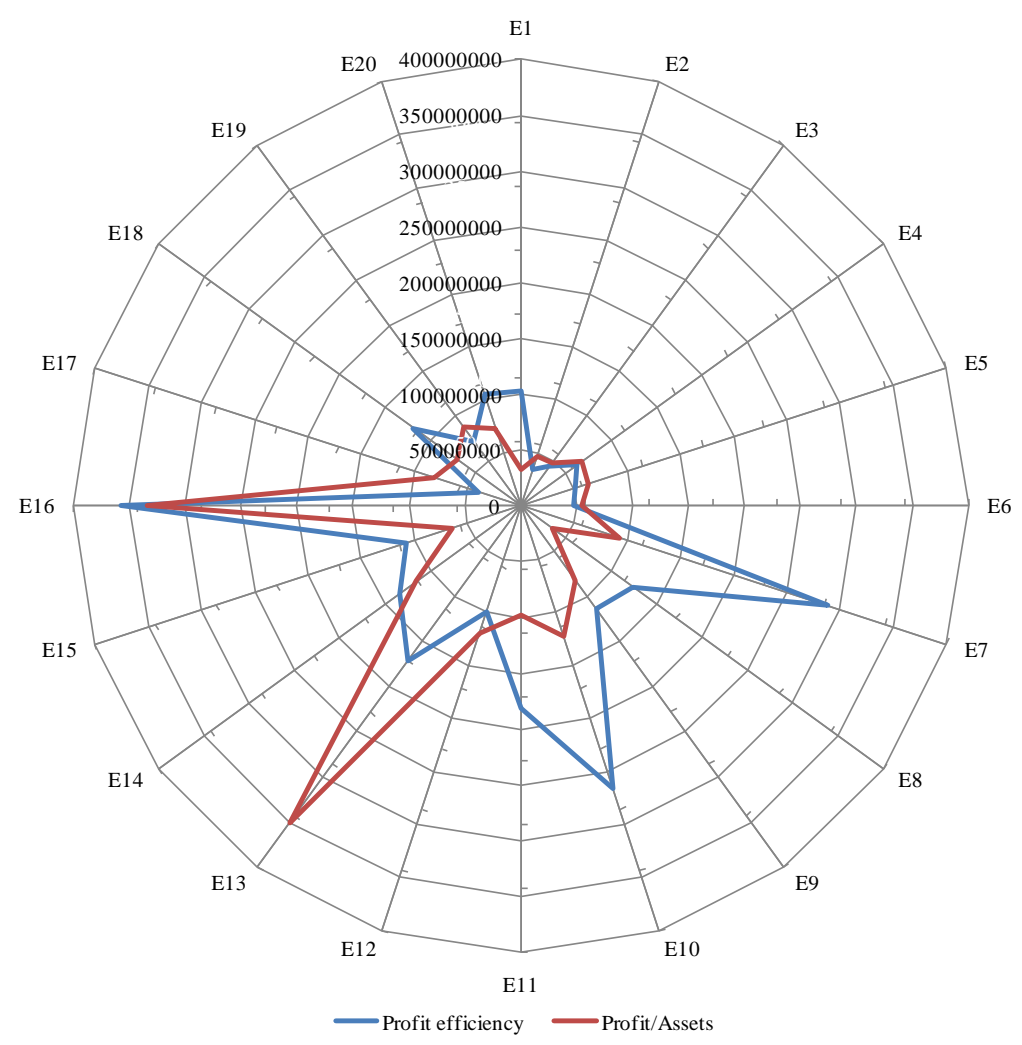

(b) 
Figure 8: Radar plot for the comparison of profit efficiency with profit per customer $a$ ) and $b$ ) profit per asset index in TL. 


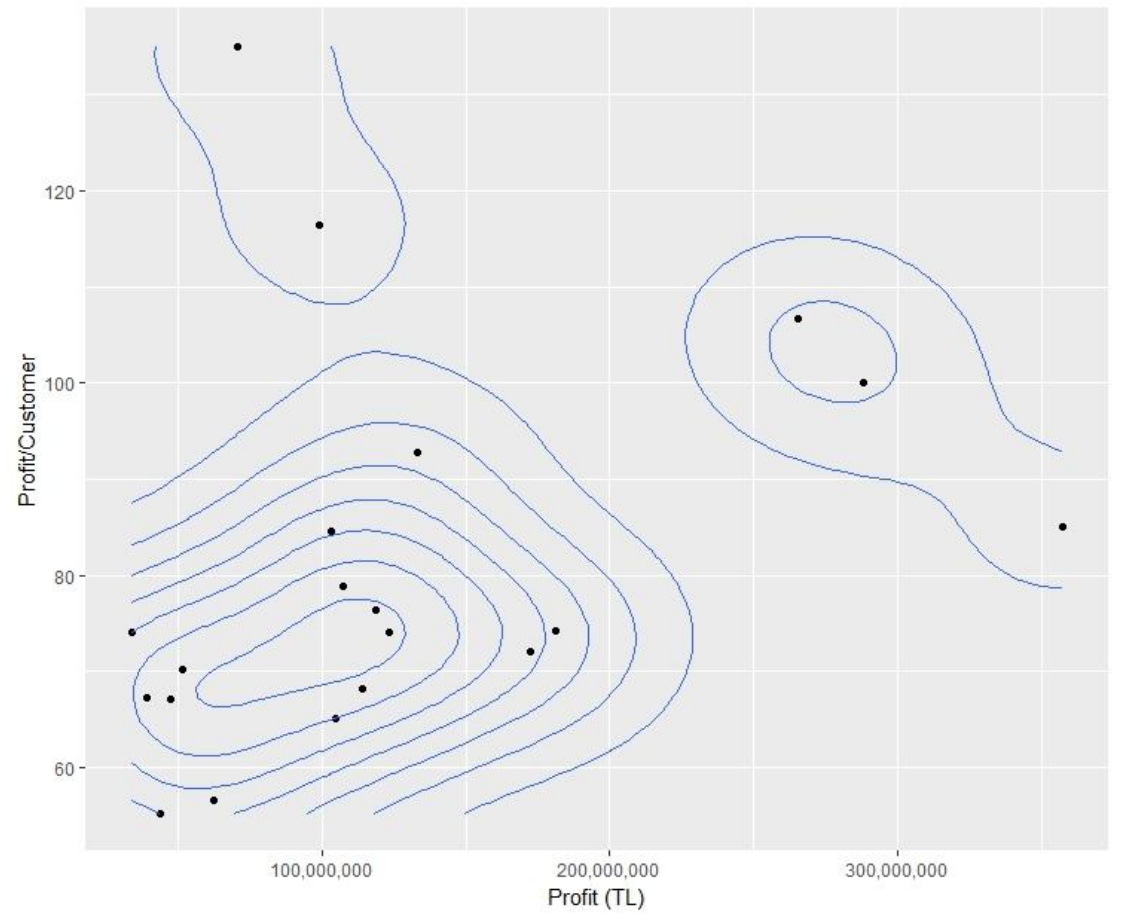

Figure 9: Scatter plots with the 2D density estimation of profit ( $\Pi$ ) and profit per customer in TL. 


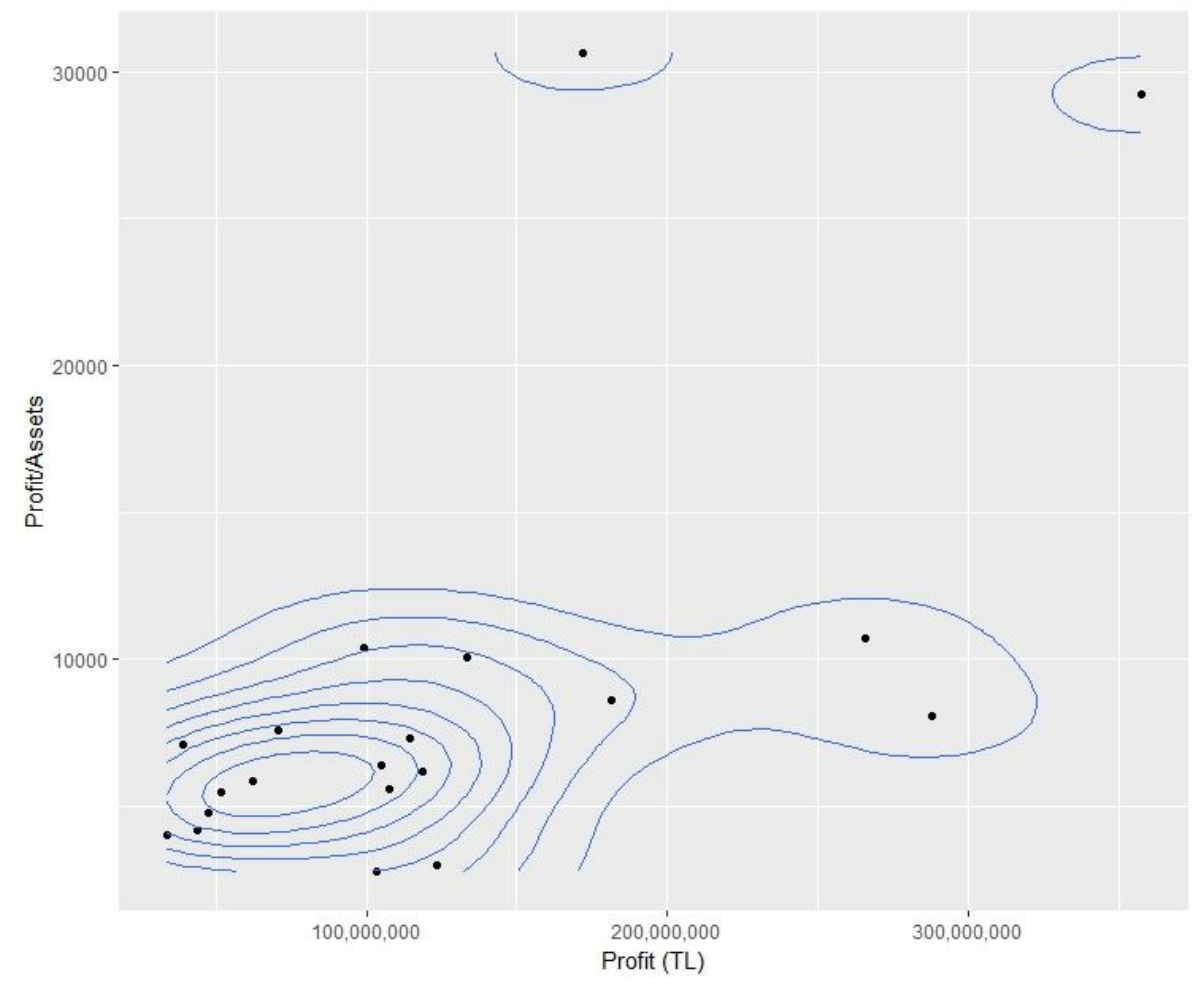

Figure 10: Scatter plots with the 2D density estimation of profit (П) and profit per asset in TL. 
Table 1: Models used to assess electricity performance using DEA models.

\begin{tabular}{|c|c|c|c|c|}
\hline Reference & Country & DEA method & Inputs & Outputs \\
\hline $\begin{array}{l}\text { Yunos and } \\
\text { Hawdon, } \\
1997\end{array}$ & Malaysia & $\begin{array}{l}\text { Malmquist } \\
\text { Index }\end{array}$ & $\begin{array}{ll}\text { - } & \text { Installed capacity } \\
\text { - } & \text { Labour } \\
\text { - } & \text { Total system losses } \\
\text { - } & \text { Public generation }\end{array}$ & - Gross electricity generation \\
\hline $\begin{array}{l}\text { Forsund and } \\
\text { Kittelsen, } \\
1998\end{array}$ & Norway & $\begin{array}{l}\text { Malmquist } \\
\text { index }\end{array}$ & $\begin{array}{ll}\text { - } & \text { Labour } \\
\text { - } & \text { Energy loss } \\
\text { - } & \text { Materials } \\
\text { - } & \text { Capital }\end{array}$ & $\begin{array}{ll}\text { - } & \text { Distance index } \\
\text { - } & \text { No of customers } \\
\text { - } & \text { Total energy delivered }\end{array}$ \\
\hline $\begin{array}{l}\text { Korhonen and } \\
\text { Syrjanen, } \\
2003\end{array}$ & Finland & CCR model & $\begin{array}{l}\text { - Operational Expenditure } \\
\text { - Cost of capital }\end{array}$ & $\begin{array}{l}\text { - } \text { Distributed Energy } \\
\text { - Quality }\end{array}$ \\
\hline $\begin{array}{l}\text { Giannakis et } \\
\text { al., } 2005\end{array}$ & UK & $\begin{array}{l}\text { Malmquist } \\
\text { index }\end{array}$ & $\begin{array}{ll}- & \text { Opex } \\
- & \text { Capex }\end{array}$ & $\begin{array}{ll}\text { - } & \text { Number of customers } \\
\text { - } & \text { Units of energy delivered } \\
\text { - } & \text { Total network length } \\
\text { - } & \text { Security of supply } \\
\text { - } & \text { Reliability of supply } \\
\end{array}$ \\
\hline $\begin{array}{l}\text { Hess and } \\
\text { Cullman, } \\
2007\end{array}$ & Germany & SFA & $\begin{array}{ll}\text { - } & \text { Labour } \\
\text { - } & \text { Length of the grid in } \mathrm{Km} \\
\text { (aerial, cable lines) }\end{array}$ & $\begin{array}{ll}\text { - } & \text { Electricity delivered } \\
\text { - } & \text { Total number of customers }\end{array}$ \\
\hline $\begin{array}{l}\text { Omrani et al., } \\
2015\end{array}$ & Iran & $\begin{array}{l}\text { PCA/Game } \\
\text { Theoretic DEA } \\
\text { model }\end{array}$ & $\begin{array}{ll}\text { - } & \text { Transformers' capacity } \\
\text { - } & \text { Number of transformers } \\
\text { - } & \text { Terrestrial network length } \\
\text { - } & \text { Aerial network length } \\
\text { - Number of employees } \\
\text { - Area }\end{array}$ & $\begin{array}{ll}\text { - } & \text { Energy Delivery } \\
\text { - } & \text { Energy consumption of } \\
\text { other customers } \\
\text { - } & \text { Industrial energy } \\
\text { consumption } \\
\text { - } & \text { Number of other customers } \\
\text { - } & \text { Number of industrial } \\
\text { customers } \\
\text { - } & \text { Number of household } \\
\text { - } & \text { Nustomers } \\
\end{array}$ \\
\hline $\begin{array}{l}\text { Yadav et al., } \\
2011\end{array}$ & India & $\begin{array}{l}\mathrm{CCR} / \mathrm{BCC} \\
\text { models }\end{array}$ & $\begin{array}{l}\text { - Operating and Maintenance } \\
\text { cost } \\
\text { - Number of employees }\end{array}$ & $\begin{array}{ll}\text { - } & \text { Energy sold } \\
\text { - } & \text { Number of customers } \\
\text { - } & \text { Duration of interruption per } \\
& \text { feeders } \\
\text { - } & \text { Distribution of line length } \\
\text { - } & \text { Transformer capacity } \\
\text { - } & \text { Total sanctioned load per } \\
& \text { square kilometre } \\
\end{array}$ \\
\hline $\begin{array}{l}\text { Gouvei, et al } \\
2015\end{array}$ & Portugal & $\begin{array}{l}\text { Value-Based } \\
\text { DEA }\end{array}$ & $\begin{array}{ll}\text { - } & \text { Mainenance and outage } \\
\text { repairing cost } \\
\text { - } \\
\text { - } & \text { Comply interruptions } \\
\text { - } & \text { Number of incidents } \\
\end{array}$ & $\begin{array}{ll}\text { - } & \text { Clients } \\
\text { - } & \text { Network lines length }\end{array}$ \\
\hline $\begin{array}{l}\text { Forsund and } \\
\text { Kittelsen, }\end{array}$ & Norway & $\begin{array}{l}\text { Malmquist } \\
\text { index }\end{array}$ & $\begin{array}{ll}\text { - } & \text { Labour } \\
\text { - } & \text { Energy loss } \\
\end{array}$ & $\begin{array}{ll}\text { - } & \text { Distance index } \\
\text { - } & \text { No of customers } \\
\end{array}$ \\
\hline
\end{tabular}




\begin{tabular}{|c|c|c|c|c|}
\hline 1998 & & & $\begin{array}{ll}\text { - } & \text { Materials } \\
\text { - } & \text { Capital } \\
\end{array}$ & - Total energy delivered \\
\hline $\begin{array}{l}\text { Zhang and } \\
\text { Bartels, } 1998\end{array}$ & $\begin{array}{l}\text { New } \\
\text { Zealand }\end{array}$ & CCR & - Data generated inputs & - Data generated outputs \\
\hline $\begin{array}{l}\text { Pombo and } \\
\text { Taborda, } \\
2006\end{array}$ & Colombia & $\begin{array}{l}\text { Malmquist } \\
\text { index }\end{array}$ & $\begin{array}{ll}\text { - } & \text { Employees in power } \\
& \text { distribution } \\
\text { - } & \text { Power lines network } \\
\text { - } & \text { Regional GDP per capita } \\
\text { - } & \text { National installed capacity in } \\
& \text { electricity generation } \\
\end{array}$ & $\begin{array}{ll}\text { - } & \text { Total sales } \\
\text { - } & \text { Total customers } \\
\text { - } & \text { Urban area served }\end{array}$ \\
\hline $\begin{array}{l}\text { Cullman and } \\
\text { Hirschhausen }\end{array}$ & Germany & CCR, SFA & $\begin{array}{l}\text { - } \text { Labour } \\
\text { - }\end{array}$ & $\begin{array}{ll}\text { - } & \text { Units sold } \\
\text { - } & \text { Number of customers } \\
\text { - } & \text { Inverse density index } \\
\end{array}$ \\
\hline $\begin{array}{l}\text { Goto and } \\
\text { Tsutsui, } 1998\end{array}$ & Japan & $\begin{array}{l}\text { Cost } \\
\text { Minimizing } \\
\text { DEA/AR }\end{array}$ & $\begin{array}{l}\text { - Nameplate generation capacity } \\
\text { - Quantity of fuel used } \\
\text { - Total number of employees } \\
\text { - Quantity of power purchase }\end{array}$ & 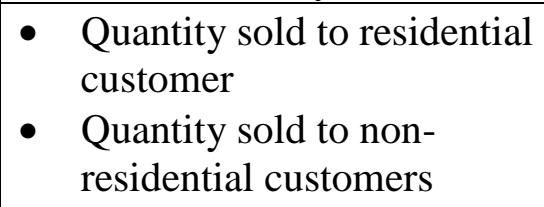 \\
\hline $\begin{array}{l}\text { Zorzo et al, } \\
2017\end{array}$ & Brazil & DEA & $\begin{array}{l}\text { - Operational costs } \\
\text { - Operational expenses }\end{array}$ & - Net revenue \\
\hline $\begin{array}{l}\text { Mirza et al, } \\
2017\end{array}$ & Pakistan & $\begin{array}{l}\text { Malmquist } \\
\text { index }\end{array}$ & $\begin{array}{ll}\text { - } & \text { Distribution losses } \\
\text { - } & \text { Peak load } \\
\text { - } & \text { Network length }\end{array}$ & $\begin{array}{ll}\text { - } & \text { Average electricity } \\
\text { consumption } \\
\text { - } \\
\text { Growth in the number of } \\
\text { customers }\end{array}$ \\
\hline $\begin{array}{l}\text { Deng et al, } \\
2018\end{array}$ & China & SFA & $\begin{array}{l}\text { - Number of employees } \\
\text { - Network length } \\
\text { - Transformer capacity } \\
\text { - Capital stock } \\
\text { - Line loss rate } \\
\text { - } \quad \text { Customer hours loss } \\
\end{array}$ & $\begin{array}{ll}\text { - } & \text { Residential quantity } \\
\text { - } & \text { Non-residential quantity } \\
\text { - } & \text { Number of residential users } \\
\text { - } & \text { Supply area }\end{array}$ \\
\hline $\begin{array}{l}\text { Arcos-Vargas } \\
\text { et al., } 2017\end{array}$ & Spain & $\begin{array}{l}\text { Standard DEA } \\
\text { model }\end{array}$ & $\begin{array}{ll}\text { - } & \text { level of remuneration } \\
\text { - } & \text { network segment } \\
\text { - } & \text { energy not supplied } \\
\end{array}$ & $\begin{array}{l}\text { - } \\
\text { - }\end{array}$ \\
\hline $\begin{array}{l}\text { Welch and } \\
\text { Barnum, } \\
2009\end{array}$ & USA & DEA-MBP & $\begin{array}{ll}\text { - } & \text { Gas } \\
\text { - } & \text { Coal } \\
\text { - } & \text { Oil } \\
\end{array}$ & - Electricity \\
\hline $\begin{array}{l}\text { Xie et al, } \\
2018\end{array}$ & China & $\begin{array}{l}\text { DEA bootstrap } \\
\text { meta-frontier } \\
\text { analysis }\end{array}$ & $\begin{array}{l}\text { - } \\
\text { - } \quad \text { Transformers capacity above } \\
35 \mathrm{kV} \\
\text { - } \quad \text { Number of employees } \\
\text { - Line loss }\end{array}$ & $\begin{array}{ll}\text { - } & \text { Non-residential users } \\
\text { - } & \text { Residential power } \\
\text { consumption } \\
\text { - } \\
\text { Non-residential power } \\
\text { consumption }\end{array}$ \\
\hline $\begin{array}{l}\text { Sartori et al, } \\
2017\end{array}$ & Brazil & $\begin{array}{l}\text { Malmquist } \\
\text { index }\end{array}$ & $\begin{array}{l}\text { Hours of training per year per } \\
\text { employee } \\
\text { - Infrastusture investements and } \\
\text { services provided primarily for } \\
\text { public benefit/economic value } \\
\text { generated }\end{array}$ & 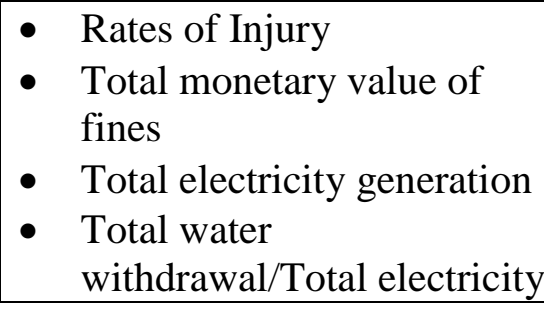 \\
\hline
\end{tabular}




\begin{tabular}{|l|l|l|l|}
\hline & & $\begin{array}{l}\text { R\&D expenditure/Economic } \\
\text { value generated }\end{array}$ & $\begin{array}{l}\text { generation } \\
\text { Total greenhouse gase } \\
\text { emision/Total electricity } \\
\text { generation }\end{array}$ \\
\hline
\end{tabular}


Table 2: Data of the analysis with the units.

\begin{tabular}{|c|c|c|c|c|}
\hline Inputs & & Intermediate Output & Undesirable Outputs & Final Outputs \\
\hline $\begin{array}{l}\bullet \\
\bullet \\
\bullet\end{array}$ & $\begin{array}{l}\text { Number of Staff (ppl) } \\
\text { Net Consumption } \\
(\mathrm{MWh}) \\
\text { Number of } \\
\text { transformators (num) } \\
\text { Length of Cables (km) } \\
\text { Installed Capacity } \\
\text { (MVa) }\end{array}$ & $\begin{array}{l}\text { - } \quad \text { Energy supply } \\
\text { (MWh) }\end{array}$ & $\begin{array}{ll}- & \text { Annual faults and } \\
\text { interruptions (num) } \\
\text { - } & \text { Energy loses (MWh) }\end{array}$ & $\begin{array}{ll}- & \text { Number of Customers } \\
& \text { (num) } \\
-\quad \text { Number of } \\
\text { Towns/Villages (num) }\end{array}$ \\
\hline
\end{tabular}


Table 3: Results of optimal values $(\beta$ and $\theta)$.

\begin{tabular}{|c|c|c|}
\hline No & $s_{1}, *$ & * \\
\hline E1 & 1 & $\mathbf{0}$ \\
\hline E2 & 1 & 0 \\
\hline $\mathbf{E 3}$ & 1 & 0 \\
\hline E4 & 1 & $\mathbf{0}$ \\
\hline E5 & 1 & 0 \\
\hline E6 & 1 & 0 \\
\hline E7 & 1 & 0 \\
\hline E8 & 1 & 0.1170 \\
\hline E9 & 1 & 0.0334 \\
\hline E10 & 1 & 0.1614 \\
\hline E11 & 1 & 0.3397 \\
\hline E12 & 1 & 0.2668 \\
\hline E13 & 1 & 0.1199 \\
\hline E14 & 1 & 0.1681 \\
\hline E15 & 1 & 0 \\
\hline E16 & 1 & 0.1170 \\
\hline E17 & 1 & 0.0334 \\
\hline
\end{tabular}




\begin{tabular}{ccc}
\hline E18 & 1 & 0.1614 \\
E19 & 1 & 0.3397 \\
E20 & 1 & 0.2668 \\
\hline
\end{tabular}


Table 4: Results of optimal values for $\hat{\lambda}_{j}^{1 *}$.

\begin{tabular}{|c|c|c|c|c|c|c|c|c|c|c|c|c|}
\hline & E1 & E2 & E5 & E6 & E7 & E10 & E12 & E13 & E15 & E16 & E17 & E19 \\
\hline E1 & 1 & & & & & & & & & & & \\
\hline E2 & & 1 & & & & & & & & & & \\
\hline $\mathbf{E 3}$ & 0.041 & 0.029 & & & & & & & & & 0.912 & 0.018 \\
\hline E4 & 0.003 & & 0.765 & & & & 0.128 & & & & 0.105 & \\
\hline E5 & & & 1 & & & & & & & & & \\
\hline E6 & & & & 1 & & & & & & & & \\
\hline E7 & & & & & 1 & & & & & & & \\
\hline E8 & & & & & & 0.061 & 0.928 & & & 0.01 & & \\
\hline E9 & & & & & & & 0.285 & & & 0.155 & 0.56 & \\
\hline E10 & & & & & & 0.754 & & & 0.246 & & & \\
\hline E11 & & & & & & 0.359 & & & & 0.158 & 0.483 & \\
\hline E12 & & & & & & & 1 & & & & & \\
\hline E13 & & & & & & & & 1 & & & & \\
\hline E14 & & & & & & 0.071 & & 0.162 & 0.345 & & & 0.421 \\
\hline E15 & & & & & & & & & 0.8 & & 0.2 & \\
\hline E16 & & & & & & & & & & 1 & & \\
\hline E17 & & & & & & & & & & & 1 & \\
\hline E18 & & & & & & 0.056 & 0.72 & & 0.224 & & & \\
\hline E19 & & & & & & & & & & & & 1 \\
\hline
\end{tabular}




\begin{tabular}{|l|l|l|l|l|l|l|l|l|l|l|l|l|}
\hline E20 & & & & & & 0.064 & 0.226 & & & & & 0.71 \\
\hline
\end{tabular}


Table 5: Results of optimal values for $\lambda_{j}^{2, *}$.

\begin{tabular}{|c|c|c|c|c|c|c|c|c|c|c|}
\hline & E1 & E3 & E4 & E6 & E7 & E11 & E13 & E16 & E17 & E20 \\
\hline E1 & 1 & & & & & & & & & \\
\hline E2 & & & 1 & & & & & & & \\
\hline E3 & & 1 & & & & & & & & \\
\hline E4 & & & 1 & & & & & & & \\
\hline E5 & & & 0.166 & 0.524 & & & & & 0.31 & \\
\hline E6 & & & & 1 & & & & & & \\
\hline E7 & & & & & 1 & & & & & \\
\hline E8 & & & & & & & 0.324 & & & 0.676 \\
\hline E9 & & & & & & & 0.185 & & & 0.815 \\
\hline E10 & & & & & 0.072 & 0.685 & & 0.243 & & \\
\hline E11 & & & & & & 1 & & & & \\
\hline E12 & & & 1 & & & & & & & \\
\hline E13 & & & & & & & 1 & & & \\
\hline E14 & & & & & & & 0.267 & & & 0.733 \\
\hline E15 & & & 0.151 & & & & & & & 0.849 \\
\hline E16 & & & & & & & & 1 & & \\
\hline E17 & & & & & & & & & 1 & \\
\hline
\end{tabular}




\begin{tabular}{|c|l|l|l|l|l|l|l|l|l|c|}
\hline E18 & & & & & & & 0.265 & & & 0.735 \\
\hline E19 & & & 0.266 & & & & & 0.734 & \\
\hline E20 & & & & & & & & & 1 \\
\hline
\end{tabular}


Table 6: Results of optimal values for Profit $\left(\Pi^{*}\right)$ and Profit Efficiency (PE).

\begin{tabular}{|c|c|c|}
\hline \multicolumn{3}{|c|}{$\Pi^{*}$} \\
\hline DMUs & & $P E$ \\
\hline E1 & 103305208 & $28.92 \%$ \\
\hline E2 & 33998863 & $9.52 \%$ \\
\hline E3 & 43905655 & $12.29 \%$ \\
\hline E4 & 62495263 & $17.49 \%$ \\
\hline E5 & 51514715 & $14.42 \%$ \\
\hline E6 & 47594324 & $13.32 \%$ \\
\hline E7 & 288152497 & $80.66 \%$ \\
\hline E8 & 123481566 & $34.56 \%$ \\
\hline E9 & 114226815 & $31.97 \%$ \\
\hline E10 & 265598151 & $74.34 \%$ \\
\hline E11 & 181406819 & $50.78 \%$ \\
\hline E12 & 98969093 & $27.70 \%$ \\
\hline E13 & 172166755 & $48.19 \%$ \\
\hline E14 & 133245324 & $37.30 \%$ \\
\hline E15 & 107498012 & $30.09 \%$ \\
\hline E16 & 357264400 & $100 \%$ \\
\hline E17 & 38954571 & $10.90 \%$ \\
\hline
\end{tabular}


E18

E19

E20
118751312

70896004

104927874
$33.24 \%$

$19.84 \%$

$29.37 \%$ 
Table 7: Results of optimal values for $\lambda_{j}^{1, *}$.

\begin{tabular}{|c|c|c|c|c|c|c|c|c|c|c|c|c|}
\hline & E1 & E2 & E4 & E5 & E6 & E7 & E10 & E12 & E13 & E16 & E17 & E19 \\
\hline E1 & 1 & & & & & & & & & & & \\
\hline E2 & & 1 & & & & & & & & & & \\
\hline $\mathbf{E 3}$ & 0.04 & 0.03 & & & & & & & & & 0.91 & 0.02 \\
\hline E4 & & & 1 & & & & & & & & & \\
\hline E5 & & & & 1 & & & & & & & & \\
\hline E6 & & & & & 1 & & & & & & & \\
\hline E7 & & & & & & 1 & & & & & & \\
\hline E8 & & & & & & & & 0.45 & & 0.13 & 0.42 & \\
\hline E9 & & & & & & & & 0.09 & & 0.19 & 0.71 & \\
\hline E10 & & & & & & & & 0.33 & & 0.39 & 0.29 & \\
\hline E11 & & & & & & & 0.36 & & & 0.16 & 0.48 & \\
\hline E12 & & & & & & & & 1 & & & & \\
\hline E13 & & & & & & & & & 1 & & & \\
\hline E14 & & & & & & & & 0.57 & & 0.13 & 0.3 & \\
\hline E15 & & & & & & & & 0.56 & & 0.02 & 0.42 & \\
\hline E16 & & & & & & & & & & 1 & & \\
\hline E17 & & & & & & & & & & & 1 & \\
\hline
\end{tabular}




\begin{tabular}{|l|l|l|l|l|l|l|l|l|l|l|l|c|}
\hline E18 & 0 & & & & & & & 0.83 & & 0.07 & 0.1 & \\
\hline E19 & & & & & & & & & & & & 1 \\
\hline E20 & & & & & & & 0.06 & 0.23 & & & & 0.71 \\
\hline
\end{tabular}


Table 8: Results of optimal values for $\lambda_{j}^{2, *}$.

\begin{tabular}{|c|c|c|c|c|c|c|c|c|c|c|c|}
\hline & E1 & E3 & E4 & E5 & E6 & E7 & E11 & E13 & E16 & E17 & E20 \\
\hline E1 & 1 & & & & & & & & & & \\
\hline E2 & & & & 1 & & & & & & & \\
\hline E3 & & 1 & & & & & & & & & \\
\hline E4 & & & 1 & & & & & & & & \\
\hline E5 & & & & 1 & & & & & & & \\
\hline E6 & & & & & 1 & & & & & & \\
\hline E7 & & & & & & 1 & & & & & \\
\hline E8 & & & & 0.2 & & & & & 0.09 & & 0.7 \\
\hline E9 & & & & 0.21 & & & & 0.32 & & & 0.47 \\
\hline E10 & & & & & & & & & 0.34 & & 0.66 \\
\hline E11 & & & & & & & 1 & & & & \\
\hline E12 & & & & 0.83 & & & & & 0.17 & & \\
\hline E13 & & & & & & & & 1 & & & \\
\hline E16 & & & & & & & & & & & \\
\hline
\end{tabular}




\begin{tabular}{|l|l|l|l|l|l|l|l|l|l|l|c|}
\hline E18 & & & & 0.59 & & & & 0.18 & 0.13 & & 0.1 \\
\hline E19 & & & 1 & & & & & & & \\
\hline E20 & & & & & & & & & & & 1 \\
\hline
\end{tabular}

